\title{
ENVIRONMENTAL AND THUNDERSTORM STRUCTURES AS SHOWN BY NATIONAL SEVERE STORMS PROJECT OBSERVATIONS IN SPRING 1960 AND 1961
}

\author{
STAFF MEMBERS 1 \\ National Severe Storms Project, U.S. Weather Bureau, Kansas City, Mo. \\ [Manuscript received December 26, 1962; revised March 8, 1963]
}

ABSTRACT

\begin{abstract}
Some examples of National Severe Storms Project observations are described, showing certain typical structures of the mesoscale environment and of large thunderstorms in the Oklahoma-Texas-Kansas region.

The "dry-line" at the $\mathrm{cT} / \mathrm{mT}$ boundary is shown to be characterized by an extremely abrupt gradient of watervapor content and temperature, accompanied by a wind-shift zone with appreciable horizontal convergence. On the moist air side, there were pronounced wavelike perturbations in the moisture and temperature fields, connected with systematic variations of the vector wind velocity.

Special pilot-ballon observations show the low-level jet as a flat sheet of southerly winds, with maximum strength generally 300 to $500 \mathrm{~m}$. above ground, and illustrate the great variations of wind speed associated with diurnal variability of stability in the surface layers. Appreciable streakiness of the velocity field is indicated by both pibal and aircraft measurements.

A description is given of a series of intense low-pressure systems observed at the surface, in association with the northwest sides of radar echoes. These depressions, which form at night, are warm and very dry relative to their surroundings, and are attended by strong, gusty surface winds.

High-level aircraft observations are illustrated, demonstrating particularly the significant disturbances of the wind field around cloud tops. An example of gust measurements in the upper portion of a thunderstorm (imbedded in strong vertical shear) shows that the lateral gust components, up to $30 \mathrm{~m}$./sec., are of the same order as the vertical gusts.

Movements of thunderstorms as shown by radar, and certain aspects of the reflectivities of tornado-bearing storms, are discussed briefly. Finally, the three-dimensional forms of large thunderstorms are illustrated, with emphasis on the organized asymmetrical structures.
\end{abstract}

\section{INTRODUCTION}

In spring 1961, the National Severe Storms Project initiated a large-scale effort designed to probe Great Plains convective storms and the environments in which they grow. Under the name "Project Rough Rider", field operations were carried out by several cooperating Government agencies. These included the National

1 Contributors to this report are A. B. Arnett, H. L. Coleman, J. T. Dooley, B. B* Goddard, J. W. Hamilton, J. T. Lee, C. W. Newton (Chief Scientist), N. E. Prosser, L.'D. Sanders, R. W. Smith, C. F. Yan Thullenar (Director), N. B. Ward, and D. T. Williams.
Severe Storms Project (NSSP) and Research Flight Facility (RFF) of the Weather Bureau; the Geophysics Research Directorate (GRD) and Aeronautical Systems Division (ASD) of the Air Force; the Federal Aviation Agency (FAA); and the National Aeronautics and Space Administration (NASA). Essential support facilities were provided by several Weather Bureau stations, the Air Weather Service, the 3d Target Acquisition Battalion at Fort Sill, Okla., the Air Force Tactical Air Command, the Air Defense Command, and the Oklahoma Air National Guard. 
Plans for the field operations, their scientific objectives, and the general facilities available during the 1961 season are outlined elsewhere $[29,32]$. The observational program in 1961 encompassed the use of specially instrumented aircraft, radar, surface recording networks, electric field measurements and cloud photography from ground stations and aircraft, and special rawinsonde and pilot-balloon observations. A more limited program in 1960 was centered mainly around the use of aircraft which penetrated severe storms. The times during which observations were made by the various components in the spring 1961 season have been summarized by Lee [20].

The goal of NSSP is broadly similar to that of the Thunderstorm Project, in its field studies of thunderstorms in Florida in 1946 and in Ohio in 1947 [9]. This is to secure a comprehensive physical description of thunderstorms and their surroundings. Analyses by the Thunderstorm Project yielded a clear concept of many of the structural features of such storms. Inauguration of the National Severe Storms Project resulted from a recognition that the giant storms characteristic of the Great Plains are basically different in some aspects, from the generally smaller storms on which the efforts of the Thunderstorm Project were concentrated. On the whole, they are more severe. Under the conditions prevalent in spring, they appear to have more highly organized asymmetrical structures than is typical of the storms described earlier.

Moreover, the development of new observational tools makes it possible to carry out certain types of measurements which were not feasible a decade ago. Another major factor is the need for observations above $25,000 \mathrm{ft}$., the greatest height represented in aircraft measurements of the Thunderstorm Project. This need arises, in a practical sense, from problems involved in the increased highlevel operation of fast aircraft in the neighborhood of storms which commonly grow to heights of 40,000 to $50,000 \mathrm{ft}$. or higher.

Another purpose in creating NSSP is to study further the mesoscale features observed at the ground, in relation to the associated convective storms. Very useful results have been obtained by the single Tornado Research airplane available since 1956 (see [16] and references therein). Expansion into a multilevel sampling program, with extensive support by ground-based facilities, provides hope of describing the three-dimensional structure of storms during an appreciable part of their life histories.

The purpose of this paper is to provide a partial glimpse of the kinds of data obtained during the operations, and of their implications for the generation and behavior of storms. Because of the broad scope of the observations, it is feasible to present only some fragmentary samples which are thought to be of salient interest.

\section{MESOSCALE STRUCTURES IN THE LOWER TROPOSPHERE}

Aircraft observations of low-level wind field.-A number of flights were carried out with the primary objective of obtaining data to describe features of the low-level wind field. A knowledge of these is essential to an understanding of processes which modify the stability and moisture fields. Of direct interest are the scales of divergence patterns, and the forms which these patterns assume.

An example is shown in figures 1 and 2 . This flight trook place in the neighborhood of a weak low-level jet stream over the Texas Panbandle. The path of the B-26, flying near $800 \mathrm{mb}$., is shown by the line of circles in figurn 2 and in relation to the larger synoptic pattern by the thin double line in figure 1. A simultaneous flight by a DC-6 (not shown) followed a zigzag path crossing the legs of the B-26 fight at nearly right angles.

The temperature field (fig. 2) is of interest mainly because it is characteristic of lower levels in the vicinity of the low-level jet [23]. High temperatures were present in the continental tropical air to the west, the general eastward decrease of temperature indicating a marked decrease of the geostrophic wind with elevation. ${ }^{2}$ Although there was a slight moisture increase eastward, the high moisture contents characteristic of maritime tropical air had not yet appeared in the area. A squall line did, however, develop the next day when the moist tongue (entering southern Texas in fig. 1) had spread northward over Oklahoma.

A principal feature shown by figure 2 is the small-scale streakiness in wind direction, indicated by the isogons. Near the central part of the flight pattern, winds were from between $165^{\circ}$ and $190^{\circ}$. In the western portion, a veering of about $45^{\circ}$ in $45 \mathrm{n}$. mi. was observed on each leg, while farther east the wind also veered to south-southwesterly in a narrow band.

The horizontal divergence may be readily computed from the isogon pattern, using the relationship $D=$ $\partial V / \partial s+V \partial \alpha / \partial n$, where $V$ is the wind speed, $s$ is distance along the current, $\alpha$ is the wind direction (radians), and $n$ is distance normal to a streamline. Over a 40-mi. wide band west of the directional minimum, there was horizontal convergence with average value $15 \times 10^{-5}$ sec..$^{-1}$, this value being considerably larger if a smaller region is considered.

Convergence was evidently present in strength through a layer of considerable depth. The strongest directional shift, centered 10-20 mi. east of a line from Lubbock to Amarillo, was marked by a cloud of dust and sand, 20-40 mi. wide with tops estimated up to $9,000 \mathrm{ft}$. In this general region, and farther north where the dust pall was not present, turbulence was experienced with occasional sharp jolts.

The results of this flight are of interest in that they reveal a systematic structure of the wind field which is of much too fine a scale to be detected by the ordinary upperwind network. Similar wind patterns are characteristic of the western boundary of maritime tropical air.

The $c T-m T$ boundary.-According to forecasting ex-

${ }^{2}$ At the rate of about $20 \mathrm{~m} / \mathrm{sec}$. per $\mathrm{km}$. This value is, of course, only indicated at flight level and is nat necessarily representative of a deep layer. 


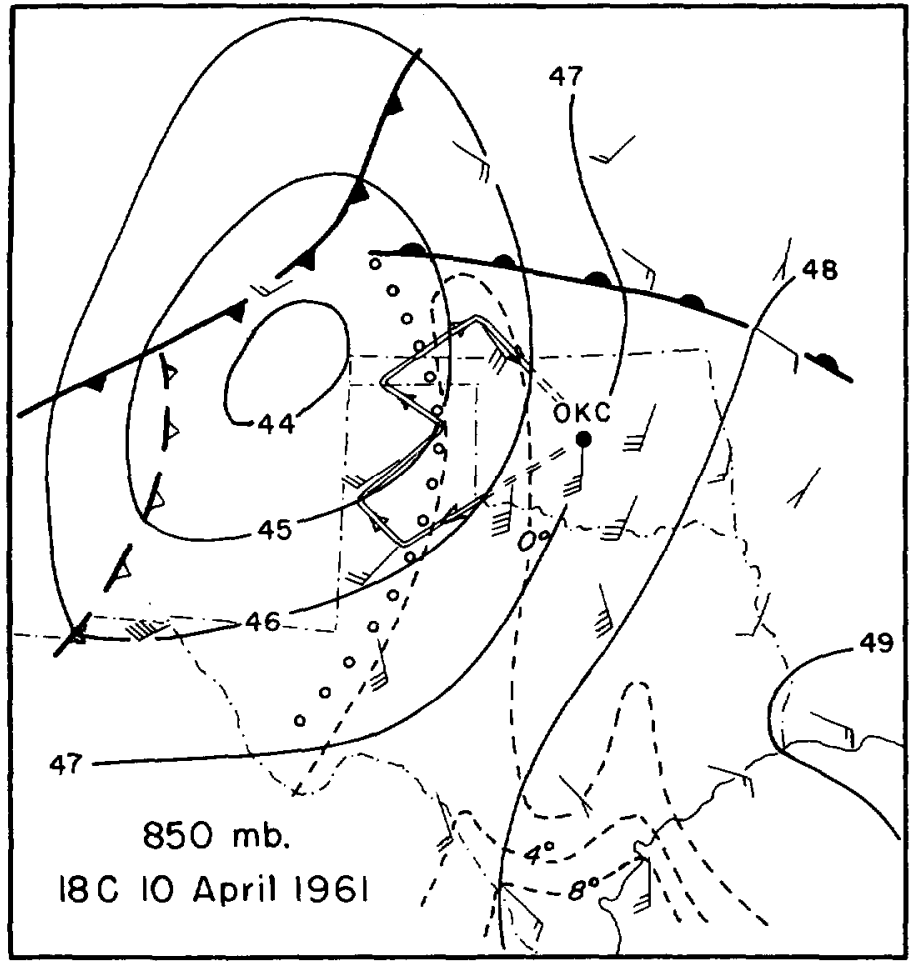

Figure 1.-Contours (solid lines, hundreds of feet) and dew point isopleths (dashed lines, ${ }^{\circ}$ C.) at $850 \mathrm{mb} ., 1800 \mathrm{cst}$, April 10, 1961. Surface fronts shown by conventional symbols; line of circles shows approximate boundary between very dry air to west and cooler, somewhat more moist, air to east. In this and following figures, winds are plotted according to convention that a full barb represents $10 \mathrm{kt}$. speed.

perience, one of the favored regions for squall lines to form is the vicinity of the "dry line", often found over the western Plain States, which marks the boundary between low-level moist $\mathrm{mT}$ air and the dry $\mathrm{cT}$ air farther west.

On May 13, 1961, a Weather Bureau DC-6 and B-26 and the GRD C-130, flying at different altitudes, undertook a joint investigation of a dry line lying over northwestern Oklahoma. Although swelling cumuli developed at the dry line, with other lines of cumulus farther east, a squall line did not materialize on this occasion, apparently because of marginal stability conditions.

The DC-6 flight path was carried out in a fashion designed to provide a number of traverses of the line, and to reveal its orientation and movement, mainly within the area shown by the hatched quadrilateral in figure 3 . The stippled area shows where the $850-\mathrm{mb}$. dewpoint exceeded $10^{\circ} \mathrm{C}$. at $1800 \mathrm{csT}$, shortly after the end of the flight. The dry line, oriented almost north-south on the average, moved eastward at an irregular speed averaging about $8 \mathrm{kt}$. The flight path, shown by dotted lines and $V$ 's (indicating the direction of flight) in figure 4 , has been adjusted so that the various legs cross the dry line along the central meridian indicated by arrows in the figure. Observations along the flight path were plotted according to distances east or west of the moisture discontinuity at

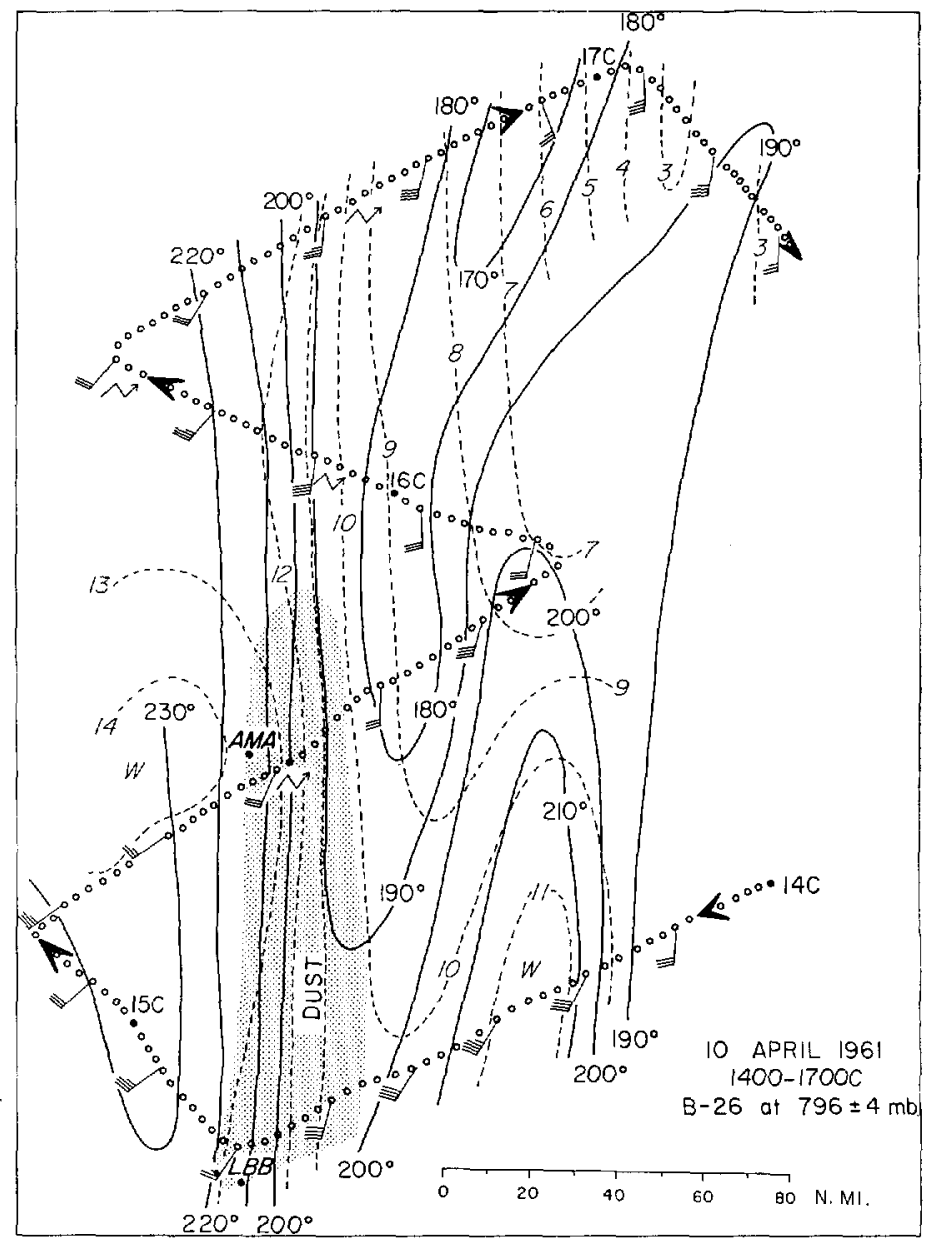

Figure 2.-Isogons (solid lines, directions according to standard meteorological convention) and isotherms (dashed lines, ${ }^{\circ} \mathrm{C}$.) at approximately $800 \mathrm{mb}$, according to aircraft measurements along the path indicated (which is also shown in fig. 1 as a thin double line).

the appropriate times. This procedure eliminates the movement of the dry line as a factor in the analysis, and provides a proper interpretation of the time changes recorded by the moving aircraft, in terms of spatial gradients of meteorological quantities.

At the bottom of the figure are shown smoothed profiles of temperature and mixing ratio, derived from averages of four east-west traverses. The mixing ratio changed by $8 \mathrm{gm} . / \mathrm{kg}$. in about $1 / 4 \mathrm{n}$. mi. (humidity was measured by an infrared hygrometer). The exact strength of the temperature gradient is not known, but the available evidence suggests that the total temperature change of about $1.3^{\circ} \mathrm{C}$. occurred in about the same distance as did the moisture change. ${ }^{3}$ Comparison of the temperature and mixing-ratio changes indicates that in this case the

\footnotetext{
3 On each traverse, the temperature fall or rise began just after the edge of the sharp moisture gradient was encountered, but the recorded temperature change clearly showed the influence of lag. Computations utilizing a lag formula, and the known lag constant of the vortex thermometer ( $10 \mathrm{sec}$. for $2 / 3$ recovery), resulted in an adequately faithful reproduction of the recorded temperature curve, when the overall temperature chango was assumed to be confined within $1 / 4 \mathrm{mi}$, distance.
} 


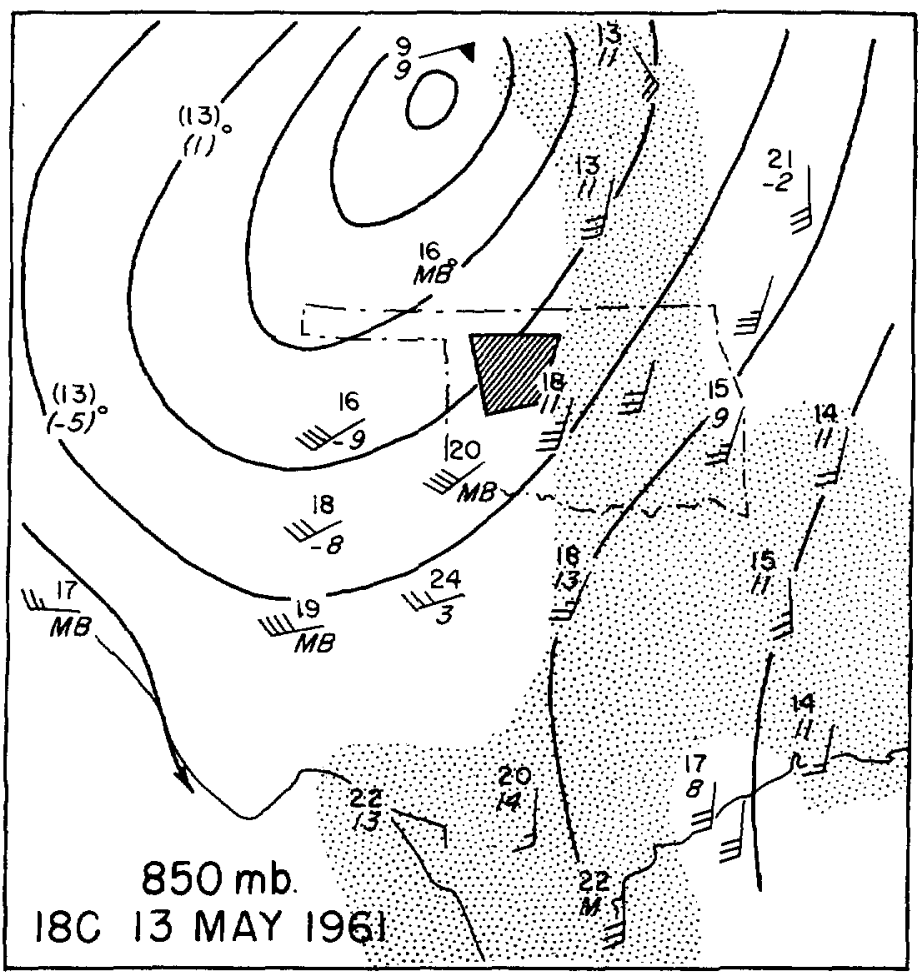

Figure 3.-850-mb. contours, 1800 cst, May 13, 1961. At stations, temperature and dew point are plotted to left. Stippling shows approximate extent of moist air (dew point greater than $10^{\circ} \mathrm{C}$.).

virtual temperature was almost equal on the two sides of the dry line, in its near vicinity. McGuire [21], in an earlier study of aircraft measurements across a dry line which was almost vertical, found the density to be very nearly the same in the moist and dry air.

Variations of wind speed were small and irregular, but the isogons indicate a systematic veering of the wind across the line. Again, there is evidence of a fine-scale streakiness in wind direction, the isogon pattern being very similar to that in figure 2 .

There is an unknown but appreciable lag in the Doppler wind-computing system, so that the gradients of wind direction shown by the figure are known to be too weak. ${ }^{4}$ Disregarding this, the directional changes averaged about $20^{\circ} \mathrm{in} 10 \mathrm{n}$. mi. The average convergence in this band was about $30 \times 10^{-5} \mathrm{sec}^{-1}$ (or stronger). Under the assumption that the convergence decreased linearly to zero at the ground, an upward motion of about $15 \mathrm{~cm}$./sec. or more would be implied at $850 \mathrm{mb}$.

Correlated distributions of water vapor, temperature, and wind.-On the afternoon of April 19, 1961, two aircraft undertook an investigation of the temperature,

4 There is no straightforward way to ascertain this lag, which is due to the necessity for the computer to time-average fluctuating ground speed and drift angle, and to inertia in the mechanical components. A study of the wind-direction profiles revealed that the recorded wind direction did not start to change until the aircraft encountered the moisture discontinuity. Thus on a westward leg the total wind shift appeared to occur on the west side, and on an eastward leg on the east side, of the dry line. Total response appeared to require about 100 sec., corresponding to about $7 \mathrm{n}$. mi. distance traveled.

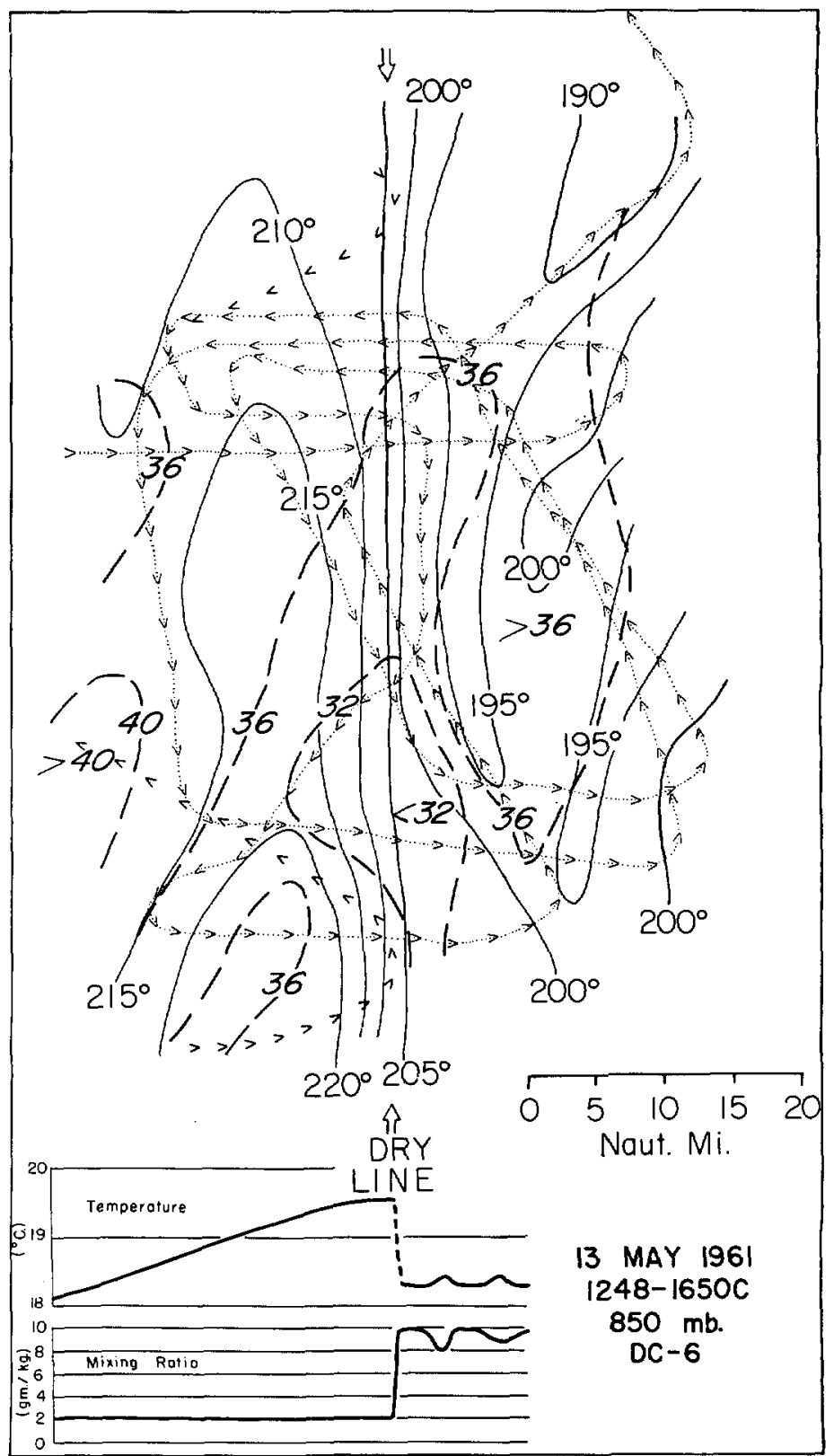

FlGURE 4.--Isogons (solid lines) and isotachs (dashed lines, knots) in vicinity of dry line, from observations within hatched area shown on figure 3 . See text.

humidity, and wind fields in the area shown by the flight paths in figure 5 (inset). These embraced the western boundary of the $\mathrm{mT}$ air mass. The DC-6 flew the indicated quadrilateral, first at 4,000 ft. then at 6,000 ft. m.s.l. Inside this box, the $\mathrm{B}-26$ flew a vertical step pattern along a line between Fairview and Buffalo, Okla., at altitudes ranging from 2,800 to $6,900 \mathrm{ft}$. On completion of this series of traverses, the $\mathrm{B}-26$ zigzagged northeastward then southwestward in order to ascertain the orientation and movement of the dry-line boundary.

Figure 6 shows the mixing-ratio distribution in a vertical section, as revealed by the B-26 traverses. This section 


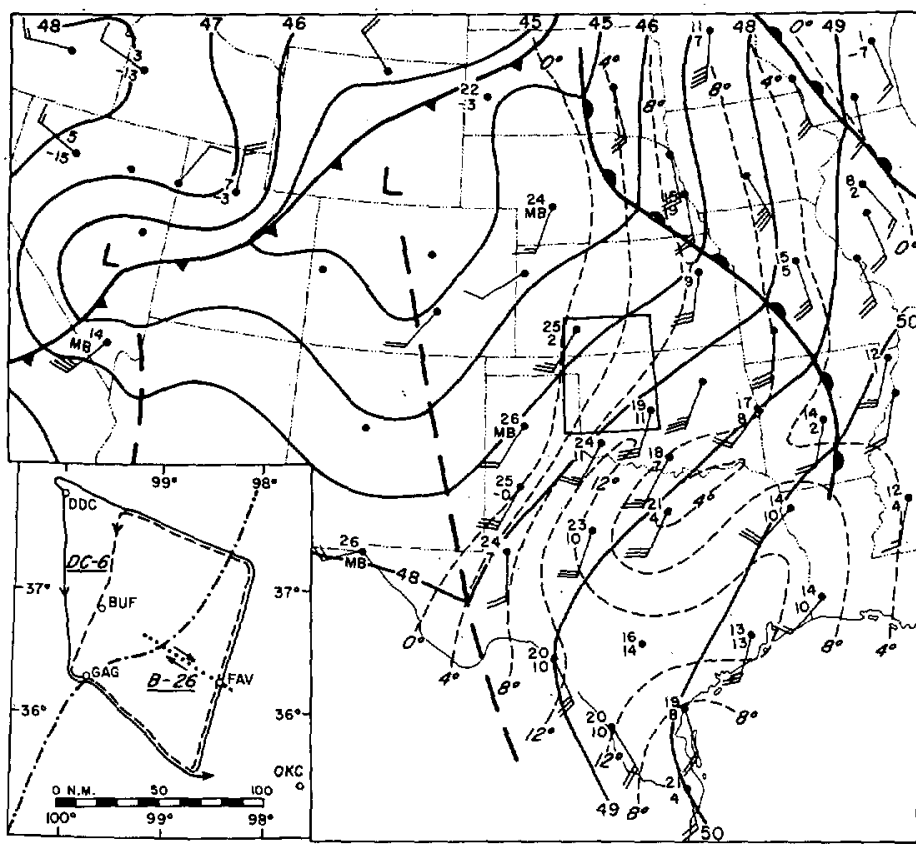

FIGURE 5.-Sectional 850-mb, chart for $1800 \mathrm{csT}$, April 19, 1961. Solid lines are contours (100-ft. interval), and dashed lines are dew point isopleths $\left({ }^{\circ} \mathrm{C}\right.$ ). The area of aireraft investigation is outlined in northwestern Oklahoma and southern Kansas. The inset shows the flight path of the DC-6 aircraft (dashed line: $4,000 \mathrm{ft}$., solid line: $6,000 \mathrm{ft} . \mathrm{m} . \mathrm{s} .1$.) and the path of the repeated B-26 traverses (dotted line). The $1800 \mathrm{csT}$ position of the dry line is shown as a dash-dotted line in inset.

was nearly normal to the dry line, which was oriented about $200^{\circ}-020^{\circ}$ true. The vertical arrangement of the reference line in this figure is not intended to imply that the boundary between moist and dry air was in fact vertical nor that it did not move. The location where the dry line was encountered moved westward between 2 and $3 \mathrm{mi}$. with reference to a visual fix, between the first and sixth traverses (1512 and $1625 \mathrm{csT}$ ) at the lowest and highest levels. This cannot be taken as an indication of the slope, because successive traverses at the same altitude, after this section was completed, indicated that the dry line was actually moving westward.

The moisture discontinuity was found to be extremely sharp, with a mixing-ratio change from $7 \mathrm{gm} . / \mathrm{kg}$. to $3 \mathrm{gm} . / \mathrm{kg}$. occurring within flight time of as little as 4 sec. (a distance of about $0.2 \mathrm{n}$. mi.). ${ }^{5}$ The moisture "pull-up" on the east side of the line is clearly evident up through the highest traverse. Of particular interest is the wavelike pattern of the moisture field, which shows four major crests of moist air that were, on the a verage, about $13 \mathrm{~km}$. apart along the direction of the flight legs. Similar variations were observed along the legs of the DC-6

5 Four seconds is the approximate response time of the infrared hygrometer. With the ultrasensitive refractometer of the GRD C-130, Cunningham [10] has measured refractive index gradients through dry lines, which indicate moisture changes of $8 \mathrm{gm} . / \mathrm{kg}$. in $250 \mathrm{~m}$, occurring in steps with much sharper gradients over small distances. At the edges of clouds associated with dry lines, gradients up to about $4 \mathrm{gm}$. $/ \mathrm{kg}$. in $2 \mathrm{~m}$, were encountered.

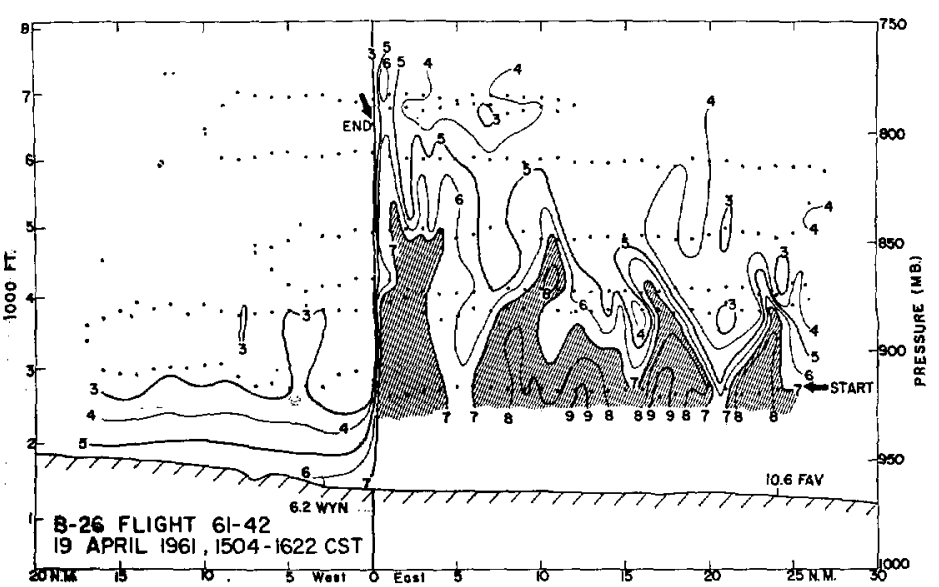

FIGURE 6.-Isopleths of mixing ratio (gm. $/ \mathrm{kg}$.) shown by traverses across dry line in northwestern Oklahoma, April 19, 1961. Dots show selected data points along aircraft path.

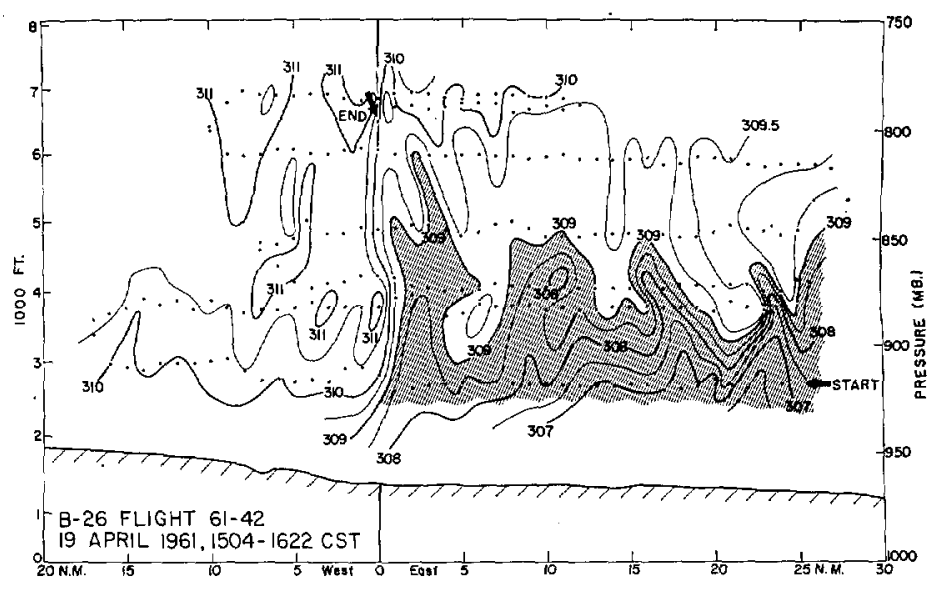

Figure 7.-Isopleths of potential temperature $\left({ }^{\circ}\right.$ K.) for same section as figure 6 .

flight east of the dry line. The locations and dimensions of these suggest that both aircraft were encountering the same tongues of disturbed air, essentially parallel to the dry line, rather than discrete cells. The possibility of cellular structure is not ruled out, however.

The moisture distribution in figure 6 is most readily accounted for in terms of the air in the crests having been lifted from the moist layer below, and the air in between having descended from the dry upper levels. This interpretation is supported by the distribution of potential temperature, shown in figure 7. Upward-bulging moist tongues are closely related to tongues of lower potential temperature, consistent with the decrease of mixing ratio and increase of potential temperature with elevation.

That the moisture and temperature patterns in figures 6 and 7 do not reflect random variations, is indicated by the appearance of the same major features on successive traverses despite the appreciable time differences between passages over the same point. 
The supposition that the patterns are produced by vertical motions is consistent with the character of the wind field (not shown). Averaged over the lower four traverses, the wind, about $25 \mathrm{kt}$. in speed, veered $24^{\circ}$ in a westward distance of $5 \mathrm{n}$. mi. across the dry line (the wind shift was most pronounced in low levels and ill defined in the uppermost traverse). Farther east, there was a fairly systematic association between the patterns of wind direction and the patterns shown in figures 6 and 7, dry warm air generally being associated with more westerly directions and moist cool air with wind directions more nearly from the south. Assuming that these variations were not entirely compensated for by variations of wind speed along the current (i.e. normal to the section), this distribution implies that horizontal convergence was present on the west sides of moisture ridges, and divergence on their east sides. (This assumption is justified on the grounds that, from other observations in this case as well as in figs. 2 and 4 , wind speed variations along the current were minor compared to variations across the current.)

Inspection of topographic charts did not reveal any features suggestive of localized heat sources or orographic rises of appropriate dimensions to account for the perturbations shown in figures 6 and 7 . It is possible that these reflect standing gravity waves set up at the dryline convergence zone. ${ }^{6}$ It may be noted that the patterns in figures 6 and 7 are remarkably similar to those described by Braham and Draginis [5], in the lee of Mount Lemmon in Arizona when surface heating sets up convection over the mountain crest. In their examples, moist and cool "bubbles" appeared with a spacing of about $2.5 \mathrm{~km}$., under conditions of weaker winds.

Because of the frequent inception of large thunderstorms or squall lines near the dry-line convergence zone, it would be desirable to find out to what degree the patterns shown in figures 6 and 7 are characteristic. These seem to be associated with bands of convection, any one of which under proper circumstances might develop into a squall line, and further aircraft investigation of their properties is in order.

Pilot-balloon observations of the low-level jet stream. At the instigation of the late Dr. Harry Wexler, a temporary special pilot-ballon network was established to secure observations in low-level jet stream situations. Wexler [35] has treated the low-level jet theoretically, as a phenomenon analogous to the Gulf Stream. In his discussion, the Rocky Mountains play a role, as a western boundary to the Bermuda High circulation, analogous to

\footnotetext{
6 This tentative supposition is not readily ruled out, because the wavelength of the simplest type gravity wave is of the same order as that indicated in figs. 6 and 7 , making allowance for the wind direction not lying in the plane of the figures. It must be accepted with caution, because the computed wavelength is only about 60 percent of the wavelength shown by the larger-scale features. Computations were made on the basis of small-amplitude waves in which no condensation occurs, an obvious oversimplification. The formula applied is $\lambda=2 \pi \bar{u} \sqrt{\theta^{*} g^{-1}\left(\partial \theta^{*} / \partial z\right)^{-1}}$, where $\bar{u}$ is the mean wind speed in the layer concerned, and $\theta^{*}$ is the virtual potential temperature.

7 This subsection briefly summarizes some of the findings of a study by Hoeker [19] which will appear in full in an early issue of this publication.
}

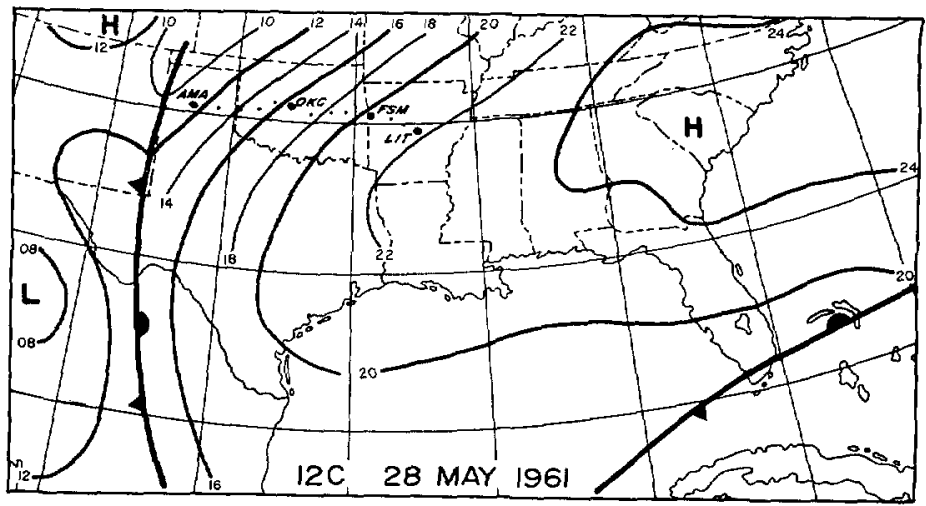

Figdre 8.-Sea level isobars (labeled in millibars; prefix 10) and fronts, 1200 CST, May 28, 1961. Locations of pilot-balloon stations shown by dots. (After Hoecker [19])

the role played by the east coast of North America as a western boundary of the anticyclonic gyre of the oceanic circulation. Among other conditions, low-level jet formation is most favored when the subtropical High is well developed and relatively far west. Under these circumstances, the westward transport of air over the Caribbean region is large, and this easterly current, being deflected northward on encountering the mountain barrier, furnishes an abundant supply of air for a southerly low-level jet east of the Rockies.

Operation of the special pilot-balloon network was inspired partly by the need for further details to embellish the theoretical treatment, and partly by the generallyrecognized importance of the low-level jet as a phenomenon influencing moisture and stability changes in convective situations.

The network consisted of 13 stations, on the average about $70 \mathrm{~km}$. apart, in a line from Amarillo to Little Rock. During the period of operation, the hoped-for condition of an intense jet, straight from the south and unpolluted by the presence of fronts or other disturbances, was never realized. However, very satisfactory observations were secured on five days, every hour during a 24-hr. period in each instance.

The general synoptic situation, at a time in the middle of one of these periods, is shown in figure 8. The sea level pattern, indicating general southwesterly flow over the line of pilot-balloon stations, changed little during the $12 \mathrm{hr}$. before and after this time.

Vertical sections illustrating the south-north component of the wind are shown for selected times in figure 9 (for a detailed description of this and two other cases, see Hoocker [19]). This particular set of observations ran from midnight to midnight, and figure 9 brings out, in a very striking way, the diurnal variations of the southerly current.

The low-level jet, up until about 0800 CST (figs. 9a-c) and again during the evening hours, is seen as a remarkably shallow sheet of strong winds. The surface of maximum wind, generally $300-500 \mathrm{~m}$. above terrain, tended 

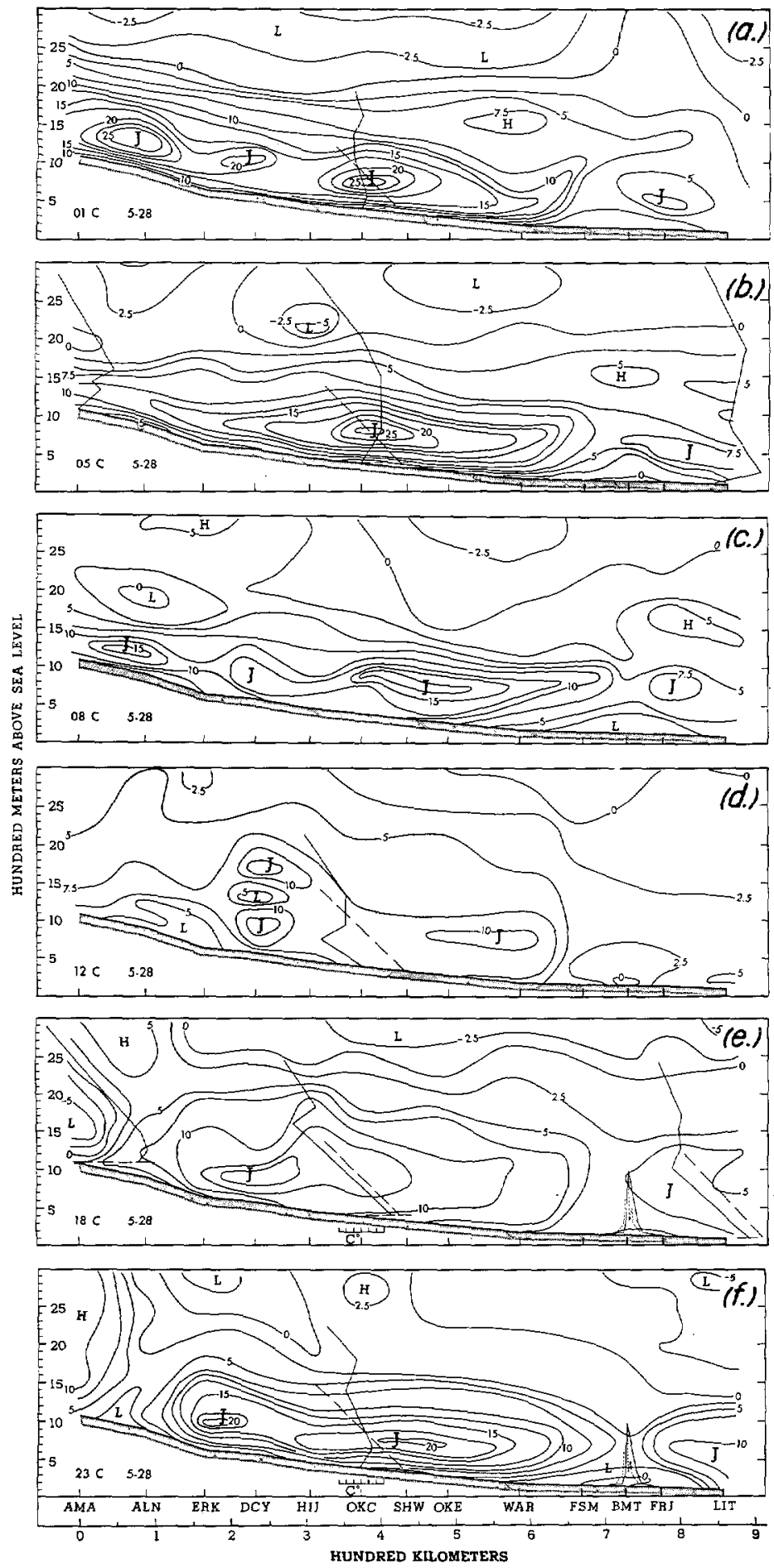

Frgure 9.--Isopleths of the northward component of wind (at intervals of $2.5 \mathrm{~m} . / \mathrm{sec}$. or about $5 \mathrm{kt}$.) in vertical section along line between Amarillo and Little Rock, at selected times on May 28,1961 . Spacing of pilot-balloon stations is shown at bottom. Temperature-height curves are shown for Amarillo (AMA), Oklahoma City (OKC), and Little Rock (LIT); dashed lines with $45^{\circ}$ slope are dry adiabats. Individual cores of the low-level jet indicated by "J" ; other relative maxima or minima of southerly wind are indicated by "H." or "L." (After Hoecker [19])

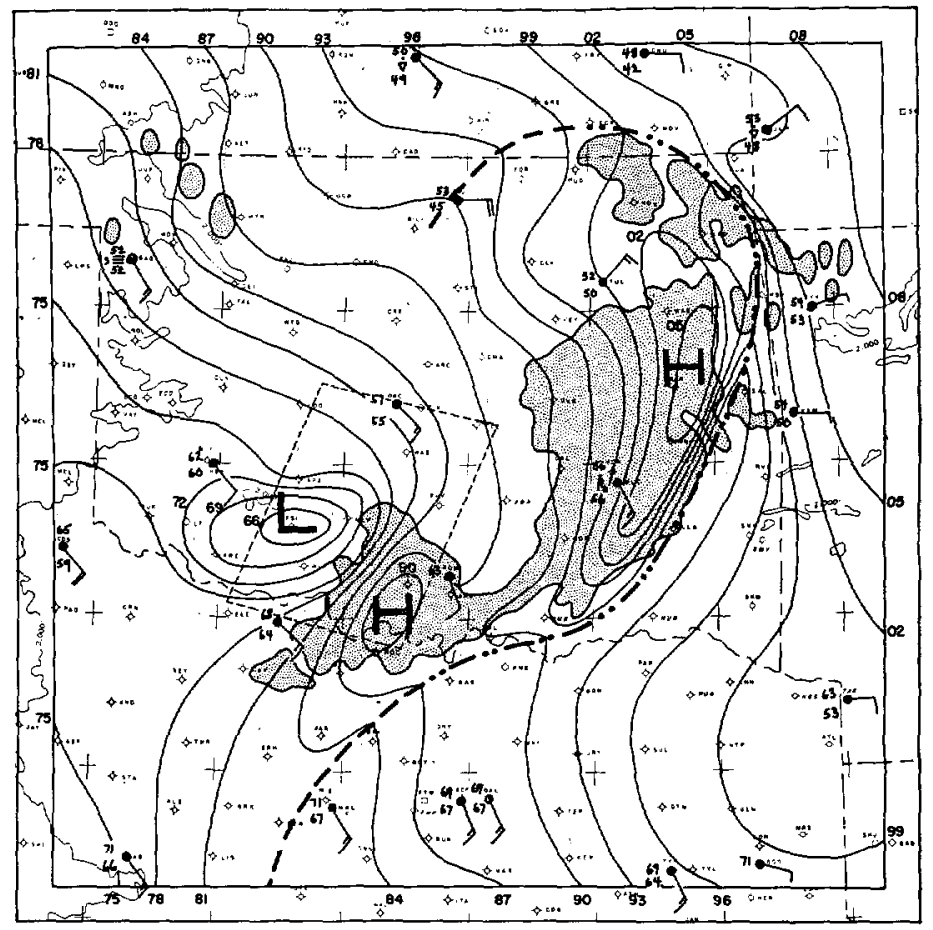

Frgure 10.-Squall line (dash-dotted line), radar echoes, and sea level isobars at 0.03 -inch intervals (labeled in hundredths; prefix 29 or 30 as whole inch) at 0300 cst, May 4, 1961.

to slope in the same manner as the earth's surface. Note that in this case (as in others) maximum winds were located generally below $1500 \mathrm{~m}$. m.s.l; thus wind observations at the $850-\mathrm{mb}$. standard isobaric surface do not necessarily provide an adequate notion of the strength of the low-level jet stream. Fragmentation into several cores of highest speed, as in figure 9a, appears to be common. The somewhat weaker winds and generally higher elevation of the jet (above terrain as represented by station elevations) near Blue Mountain (BMT) was evidently a local influence of the higher terrain both north and south in this region (fig. 9f).

During night when the surface layer was very stable (see sounding curves on figs. $9 \mathrm{a}, \mathrm{b}$, and $\mathrm{f}$ ), the low-level jet was well developed and coherent, while in daytime when the surface boundary layer was unstable (figs. 9d, e), winds were much weaker and poorly organized. Maximum wind speeds were subgeostrophic during the day, and strongly supergeostrophic (being up to 1.75 times the surface geostrophic wind speed) in early morning, on all three days studied by Hoecker. This behavior has been explained by Blackadar [3] on the basis of diurnal variations of frictional coupling between the air in lower levels and the earth's surface, and an inertial oscillation which results from this. It may be mentioned incidentally that Hoecker found no evident relationship between the height of the level of maximum wind, and the heights of stable layers above the surface. Also, on one day when radiation was diminished by cloudiness, the 

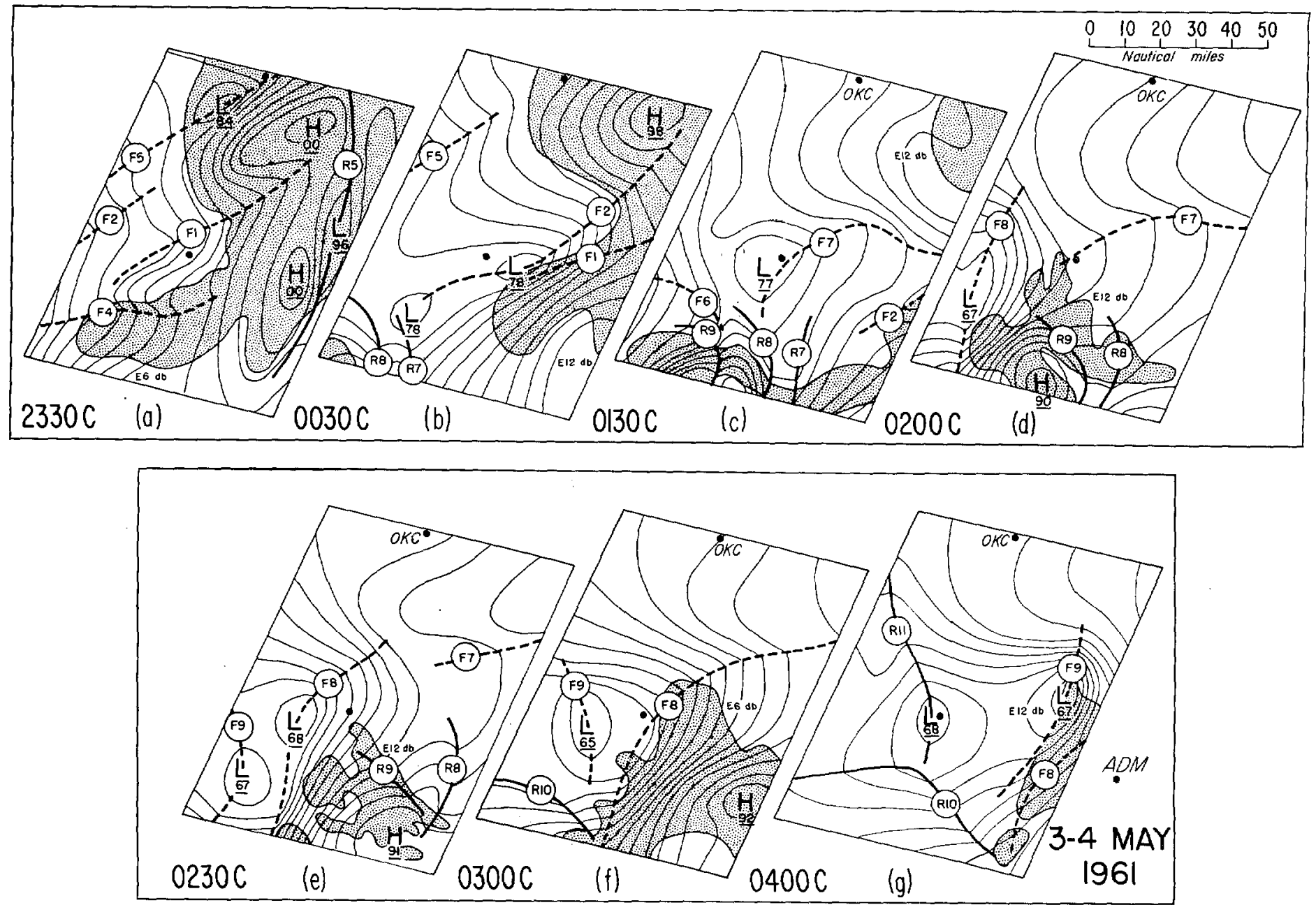

FIGURE 11.-Sea level isobars at 0.02-inch intervals, trough lines (dashed), and radar echoes over Beta network (location shown by dashed quadrilateral in fig. 10), at intervals from 2330 CST, May 3 to 0400 csT, May 4, 1961. Encircled symbols identify individual pressure troughs. Underlined numbers indicate central pressures in low and high centers. ADM=Ardmore, Okla., rawinsonde station relative position.

diurnal variation of stability in the lower layers was relatively small and the diurnal variation of wind speed, though still present, was much less pronounced than on the two clear days he studied.

\section{MESOSCALE ANALYSES OF DISTURBANCES ASSOCIATED WITH THUNDERSTORMS}

A surface network designed for the study of mesoscale disturbances has been operated in the Great Plains area since 1951 [31]. The 1961 NSSP "Alpha" network [14] consisted of about 200 stations, 30 to $40 \mathrm{mi}$. apart, in Oklahoma, the southern half of Kansas, and the northern half of Texas. All stations are equipped with microbarographs (set for one drum revolution in $12 \mathrm{hr}$.), and most have hygrothermographs and recording rain gages. In spring 1961, a finer-scale "Beta" network was installed, consisting of 36 stations $10-15 \mathrm{mi}$. apart in south-central Oklahoma. In addition to barographs, hygrothermographs, and recording rain gages, each of these stations is provided with wind direction and speed recorders.
One of the most interesting features revealed by the surface network data is the structure of pressure couplets such as that shown in figure 10. Somewhat related configurations have been described earlier, notably by Williams [36], Brunk [7], and Fujita [13]. A dominant feature in figure 10 is the thunderstorm High, whose origin is generally attributed to the production of dense air in lower levels by evaporative cooling. This High followed closely behind an intense pressure trough, which was fairly well identified with the eastern edge of an extensive mass of radar echoes. The large echo in southern Oklahoma, connected by a narrow isthmus with the main echo northeast, was a fairly recent development.

Figure 11 shows a series of isobaric analyses, at halfhourly to hourly intervals, encompassing the period when the southwestern echo of figure 10 passed over the southern part of the Beta network. In figure 11a, the principal mesohigh (identified with the one in eastern Oklahoma in fig. 10) is shown. West of the High as well as to its east, several distinct troughs were identifiable.

By 0030 csT (fig. 11b), the first of a series of intense 
low pressure centers had formed. Although the interval between the charts shown here is too large to describe the continuity adequately, it can be seen that the pressure field changed markedly from time to time. The southwesternmost low center in figure $11 \mathrm{~b}$ is seen farther northeast in figure $11 \mathrm{c}$, but it was engulfed a half hour later (fig. 11d), as another low center (on line F8) entered the southwestern portion of the network. The latter Low was then replaced by an intense Low farther west (F9) which passed all the way across the network (figs. $11 \mathrm{~d}-11 \mathrm{~g}$ ). Still another low center, west of F9, is seen on the last chart.

The most intense of these depressions (F8 and F9) appeared to be closely associated with the northwestern side of a thunderstorm cluster, just entering the southwestern corner of the network in figure $11 \mathrm{~b}$, which progressed east-northeastward at a speed of roughly $25 \mathrm{kt}$. (this echo is identifiable with the large southwestern echo in fig. 10). The individual low centers moved faster, at speeds of $33 \mathrm{up}$ to about $50 \mathrm{kt}$.

The traces in figure 12 and the maps in figure 13 (corresponding to fig. 11f) illustrate some of the salient features associated with the small-scale low pressure systems. They were characterized by appreciably higher temperature and lower relative humidity than in the surroundings. Detailed analyses at 5-min. intervals indicated that bursts of higher temperature and dry air originated at particular localities, then spread laterally to cover an extensive region (in fig. 13a, the boundaries of both an old and a newly-generated warm cell are shown).

As seen in figures 11c-11f (also fig. 10), a well-developed High was associated with the southern or southeastern part of the radar echo (it is worthy of note that although

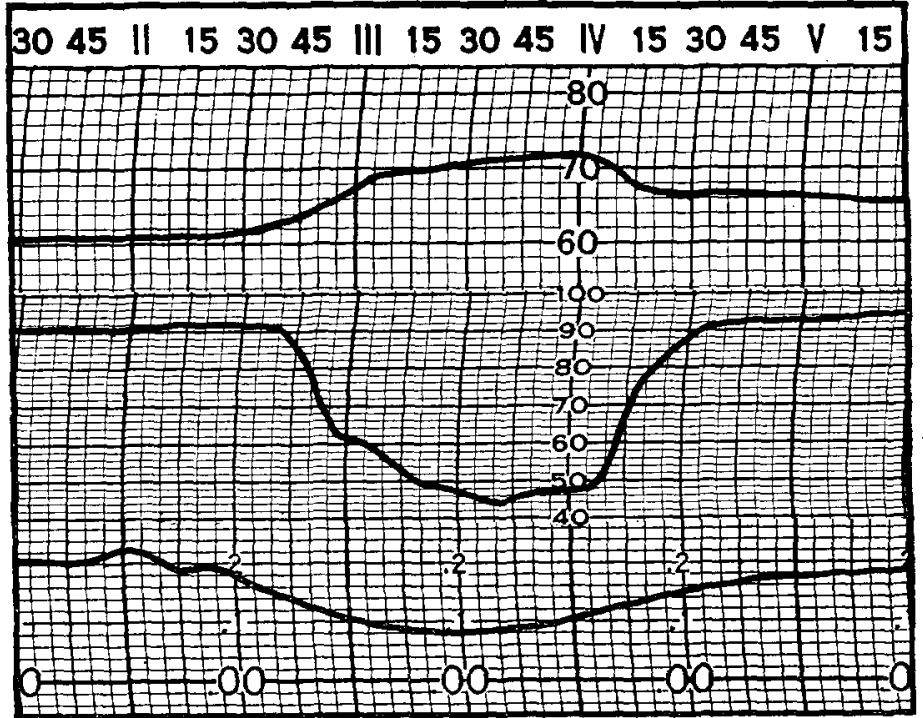

Figure 12.-Portion of surface recordings at Beta network station 22 (at heavy central dot in fig. 11), early morning of May 4, 1961. Temperature in ${ }^{\circ} \mathrm{F}$. (upper trace); relative humidity in percent; pressure in inches. Instruments are uncalibrated, and only relative values are indicated.

rainfall rates up to $0.30 \mathrm{in}$. per half hour were observed up until $0230 \mathrm{cs}$, the greatest half-hour amount recorded later was 0.05 in.). Between this High and the low center in figure 11f, the pressure gradient was $0.24 \mathrm{in}$. $(8.2 \mathrm{mb}$.) in a distance of $25 \mathrm{n}$. mi. The surface wind was light in the southeastern, but fairly strong and gusty in the western part of the region of strong pressure gradient (fig. 13c). Maps at other times showed generally southeasterly winds,

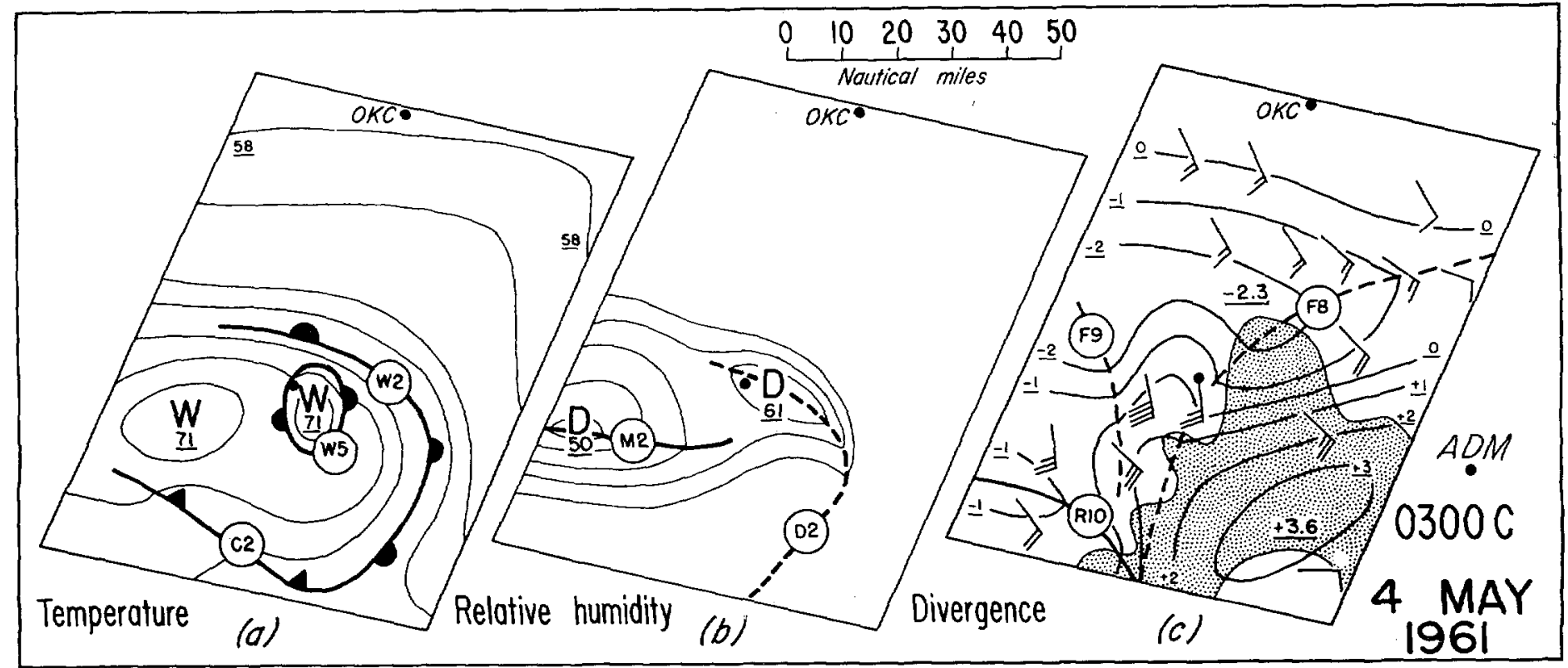

FigURE 13.-Charts of Beta network, $0300 \mathrm{csT}$, May 4, 1961, showing (a) surface isotherms at $2^{\circ}$ F. intervals, maximum temperatures underlined; (b) isopleths of relative humidity at intervals of 10 percent, minimum values underlined; and (c) surface wind (full barb, $10 \mathrm{kt}$.) and horizontal divergence $\left(10^{-4} \mathrm{sec}^{-1}\right)$. OKC=Oklahoma City, ADM=Ardmore, Okla.

$684076-63-2$ 
of diminished speed, blowing toward higher pressure on the northwestern sides of the low centers. ${ }^{8}$

The lack of geostrophic control, indicated by flow almost normal to the isobars over much of the area, is to be expected since an air particle spends only about an hour in the region of strong pressure gradient. Surface divergence up to $3.6 \times 10^{-4} \mathrm{sec}^{-1}$ was present beneath the western edge of the radar echo, with convergence up to $2.3 \times 10^{-4}$ sec. $^{-1}$ in the low-pressure region north and west (the measuring interval used was $20 \mathrm{n}$. mi.; larger values of divergence would be observed in more confined regions). There was no evidence of cyclonic rotation as would be suggested by the surface isobars; vorticity was in fact anticyclonic in the vicinity of the low centers.

Since the air approaching the Low blew from a region of cooler surface temperatures, it may be inferred that the heating and desiccation resulted from a transfer of properties from aloft. Although this could be accomplished partly by eddy transfer, organized subsiding motions are suggested by the presence of surface divergence of significant magnitude along most of the path followed by the air in flowing from the High to the low-pressure trough. Moreover, a rawinsonde was released at 0501 CST from Ardmore (position relative to network is shown (ADM) beside figs. $11 \mathrm{~g}$ and $13 \mathrm{c}$ ) in a location near the southern edge of the warm Low. Above a cool surface layer, dry (29 percent relative humidity) and considerably warmer (by as much as $10^{\circ} \mathrm{C}$. at $900 \mathrm{mb}$.) air was shown here than at any of the surrounding stations.

The phenomenon described briefly above presents a challenging problem, both because of its curious nature and the practical consequences of the associated weather characteristics. It appears that the generation of these warm, dry low-pressure systems, which are very commonly observed during the night hours, may reflect a descending branch of the overall circulation of the thunderstorm, which plays an important role in its behavior. If their formation and maintenance is indeed evidence of organized subsidence on the west sides of storms (different from the sinking of rain-cooled air within the storm), this must evidently have a significant influence on the development and motion of storms. The lack of adequate observations to describe conditions above the surface layers precludes formulation of a complete physical explanation at the present time.

\section{AIRCRAFT OBSERVATIONS AT HIGH LEVELS}

Disturbances of wind field near tops of storms.-Because of the large space- and time-gaps between regular aerological soundings, aircraft measurements of upper winds and other elements are of great value both in defining the

\footnotetext{
8 In a stationary field without frietion, Bernoulli's relationship indicates that air flowing from the region of highest pressure to the region of lowest pressure, and starting with no velocity, would achieve a speed of about $70 \mathrm{kt}$. (the strongest wind observed in this case was $40 \mathrm{kt}$.). With an eastward movement of the pressure system (as was observed), this theoretical speed would be diminished. The limited number of wind reports in fig. 13c is due to recorder malfunctions; unreliable stations have been eliminated. Reasonably reliable divergence computations could be made, despite the limited observations at a given time, by making ase of time continuity.
}

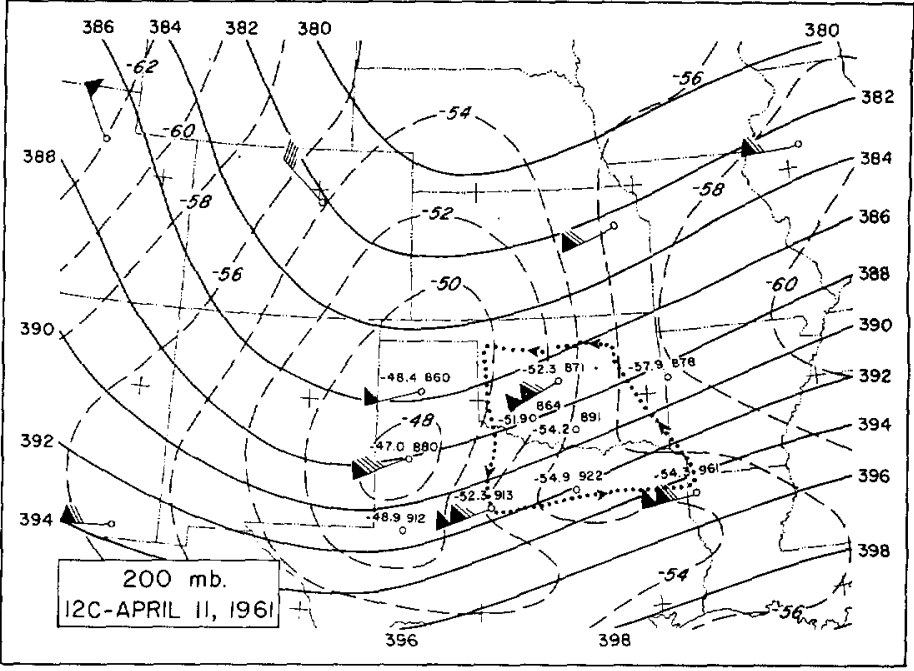

Figure 14.-200-mb, chart, 1200 CST, April 11, 1961. Contours labeled in hundreds of feet. At stations, temperature $\left({ }^{\circ} \mathrm{C}\right.$.) at left, height at right; in wind symbols, a flag represents $50 \mathrm{kt}$.; a full barb, $10 \mathrm{kt}$.

medium-scale environmental conditions and the disturbances associated directly with convective storms.

Figure 14 shows the flow pattern and isotherms at 200 mb. at 1200 CST April 11, 1961. The only aerological observations available were the few winds shown, plus special radiosonde observations over a small area. (Contours and isotherms outside this area were constructed by interpolation between analyzed charts $6 \mathrm{hr}$. before and after.) The track of the B-57, which carried out a "pre-convection" flight from about an hour before to an hour after the time of figure 14, is indicated by a dotted line.

Selected observations at flight level $(190 \mathrm{mb})$ are shown in figure 15. The isotherms in the interior of this figure were constructed with the aid of the several radiosonde observations a vailable (these being plotted at the locations of the balloons when at altitude). In a very broad sense, the isotherms are similar to those in the corresponding region of figure 14, reflecting the presence of a pool of warm air above the tropopause in the trough to the west, and an east-west band of cold air in the southern pa:t. Both of these features, in the configuration shown in figure 14, were evident in the analyses $6 \mathrm{hr}$. before and $6 \mathrm{hr}$. after.

The temperature distribution in the northeastern portion of the flight pattern (fig. 15) differs appreciably from that in figure 14. Although part of this difference is due to the lack of detailed observations in this area of figure 14 , it is for the most part real, being due to the separation of $10 \mathrm{mb}$. between the $200-\mathrm{mb}$. surface and the flight level, which was above the tropopause in this region. ${ }^{9}$ Although

\footnotetext{
9 Note that $\mathrm{OKC}$ was $1.3^{\circ} \mathrm{C}$. warmer at $190 \mathrm{mb}$. than at $200 \mathrm{mb}$., while at the other radiosonde stations the $190-\mathrm{mb}$. temperatures ranged from $0.1^{\circ} \mathrm{C}$. to $1.8^{\circ} \mathrm{C}$. cooler than at $200 \mathrm{mb}$. The strong north-south temperature gradient indicated by the aircraft observations is supported by the radiosonde observations at $190 \mathrm{mb}$; these also indicate a much weaker gradient at $200 \mathrm{mb}$.
} 


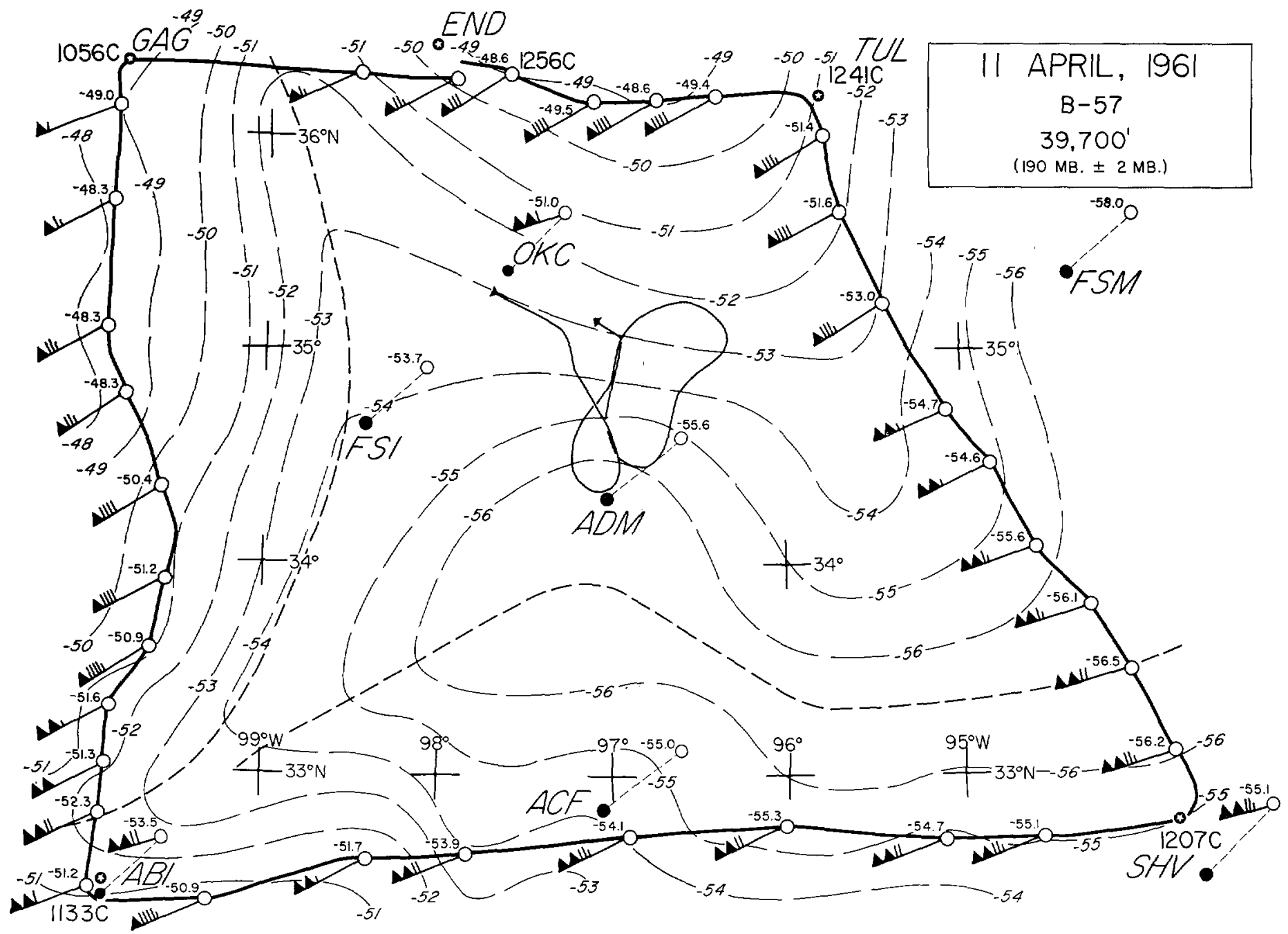

Frgure 15.--Selected winds and temperatures along track of B-57, near noon cst, April 11, 1961. Winds and temperatures (at 190 mb.) given by aerological stations are plotted on open circles, indicating locations of balloons. Times of balloon observations (at altitude) are all between 1200 and $1330 \mathrm{csT}$. Long-dashed lines, 190-mb. isotherms. (After Arnett [1])

the temperature variations with height were so complicated as to inhibit an unambiguous interpretation, it appears that the short-dashed lines in figure 15 , where the aircraft observations indicated clear reversals of the horizontal temperature gradient, are identified with intersections of the tropopauses commonly associated with the polar front zone and the subtropical jet stream.

The winds shown along the flight path in figure 15 were computed by a Doppler radar navigation system: As is characteristic of aircraft measurements, these winds contained in their raw form systematic errors associated with airspeed and compass-heading or drift-angle errors. An effort is made to determine these by comparison of measured winds on different aircraft headings. The winds shown have been adjusted by application of such empirically-determined corrections which are taken to remain constant throughout the flight. Comparison of the aircraft winds with those at rawinsonde stations near which the flight passed, encourages confidence in their accuracy. ${ }^{10}$

In general, the aircraft data indicate a wind field of almost uniform direction, with cyclonic shear averaging about $7.5 \mathrm{~m}$./sec. per $100 \mathrm{~km}$. (inspection of the observations plotted in fig. 15 reveals, however, that the shear was appreciably stronger or weaker over more limited segments of the flight track). Successive isotach analyses indicated that wind speeds generally decreased over the area during the afternoon, as the jet stream axis (over northern Texas) moved southward on approach of the upper trough.

In mid-afternoon of the same day, the B-57 undertook a second flight for the purpose of measuring disturbances

10 The exception to close agreement is the wind at Oklahoma City, which was considerably stronger than that indicated by the B-57 at points upstream and downstream. The existence of this wind speed, which also appeared on an observation $11 / 2 \mathrm{hr}$. later, is unexplained; it is out of line with Oklahoma City observations before and after, and with continuity of the broadscale isotach analyses $6 \mathrm{br}$. earlier and later. 

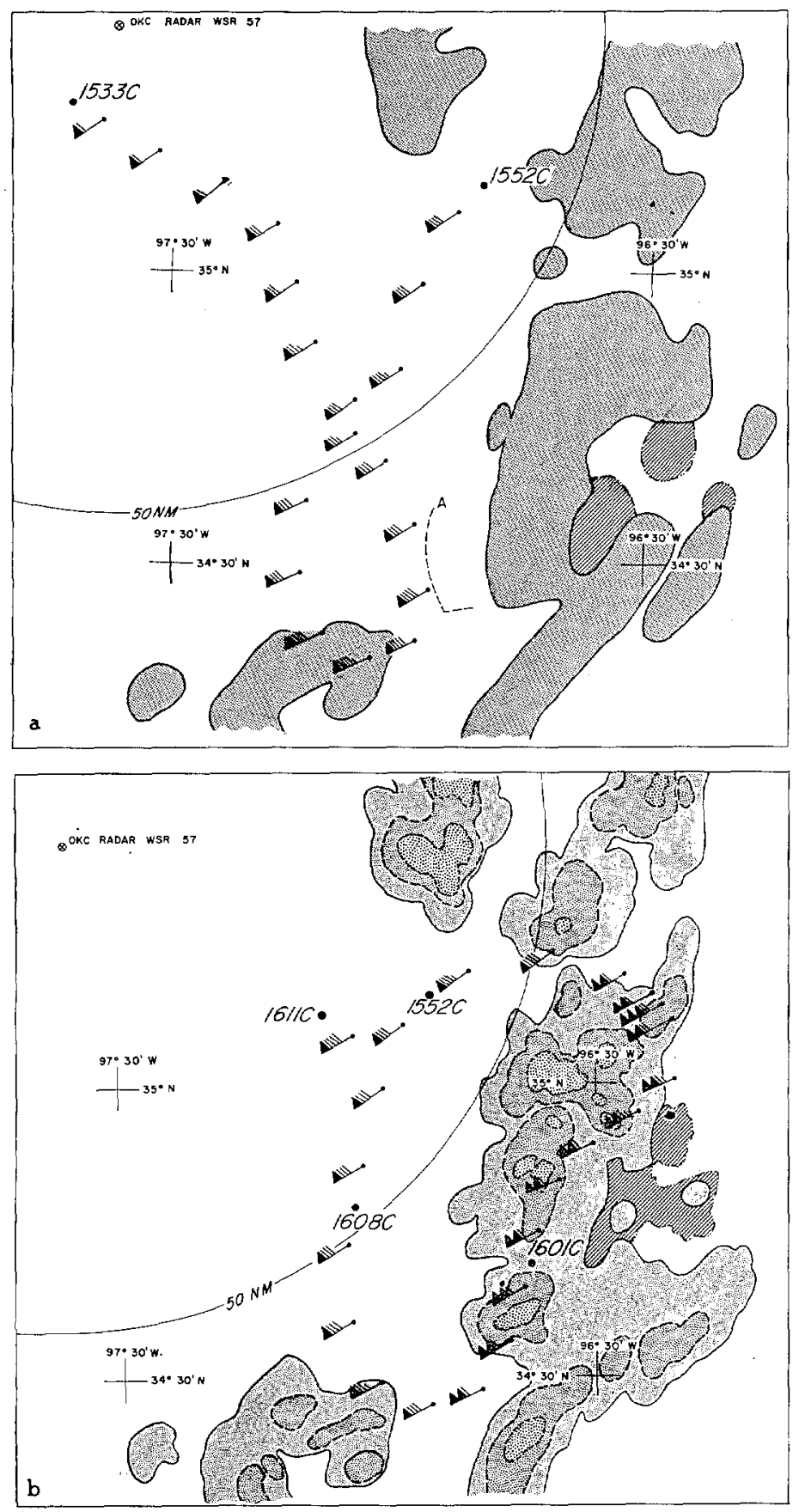

FIGURE 16.-Two portions of flight (a) west of, and (b) around a segment of a squall line southeast of Oklahoma City on April 11, 1961 (times indicated at certain points along flight track). In (b), outer contour corresponds to no radar attenuation; inner contours, 18 and $33 \mathrm{db}$. attenuation. (After Arnett [1].)

of the wind field around a squall line which had developed southeast of Oklahoma City (flight track shown by solid line in interior of fig. 15). Winds observed on this flight are shown, generally at 1 -min. intervals (about $7 \mathrm{n}$. mi. distance traveled), in figure 16. At flight level of 39,000 ft., the aircraft cleared all cloud tops although there were some turrets which extended higher.

Over the first portion of the flight (fig. 16a), in the essentially cloud-free region west of the squall line, there was no significant variation of wind other than a general cyclonic shear somewhat stronger than the average shear indicated in figure 15. In the remaining portion (fig. 16b) in which a segment of the squall line was circumnavigated, very appreciable variations are evident. The northnortheastward leg (to the west of the radar echo) was at an estimated distance of $1 / 2 \mathrm{mi}$. from the visible edge of a shelf extending upwind from the convective system. The south-southwestward leg was reported to be mostly about this distance from the east side of the cloud system (referring to the cumulus buildups reaching highest elevation, associated with the higher-reffectivity cores shown by the radar contours in fig. 16b). From the track of the aircraft as shown by ground radar, which agreed very closely with that recorded by the navigation system, it is evident that the aircraft was over the eastern part of the precipitating cloud, where the tops were well below flight level.

As seen from figure $16 \mathrm{~b}$, the winds east of the main cloud system were on the average $30 \mathrm{kt}$. stronger than those on the west side. This variation, over an average distance of $45 \mathrm{~km}$. along the streamlines, accounts for the major part of the mean horizontal divergence of $46 \times 10^{-5}$ sec. $^{-1}$. It may be noted that this corresponds to typical values of divergence measured in mesoscale thunderstorm Highs at the earth's surface [13], when areas of a corresponding size are considered. Over the more restricted region occupied by the active storm cores, much more intense divergence must, of course, have been present.

To account for a downwind increase of wind speed from 80 to $110 \mathrm{kt}$., a pressure drop of about $2.5 \mathrm{mb}$. along the streamlines from the west to the east side would be required. One interpretation is that the winds responded to a nonhydrostatic pressure field arising from the presence of the slow-moving (about $30 \mathrm{kt}$.) cloud system in a fastmoving field of flow. According to analogy with experimental measurements around obstacles in wind tunnels, pressures in excess of the hydrostatic pressure should be expected on the relative upwind sides, and pressure deficits on the downwind sides, of obstacles [24]. The influence of flow over the tops of squall-line clouds has not been examined; however it is evident that in accord with Bernoulli's principle an increased speed would be required, along with a decrease of pressure below that in the undisturbed surroundings.

Another interpretation, not necessarily incompatible with this proposition, is that the divergence shown in figure $16 \mathrm{~b}$ reflects an influence of the upper branch of the storm circulation where air ascending from below spreads out laterally. The presence of divergence of roughly this magnitude has been indicated earlier by wind measurements made by the GRD "Project Jet Stream" B-47 in traverses through the top of a storm [22].

In the northeastern portion of the loop around the storm, a maximum wind speed of $170 \mathrm{kt}$. was recorded. Anomalous winds of this sort have been observed over short segments of other flights, apparently in association with channeling of the flow around or over cloud turrets. 

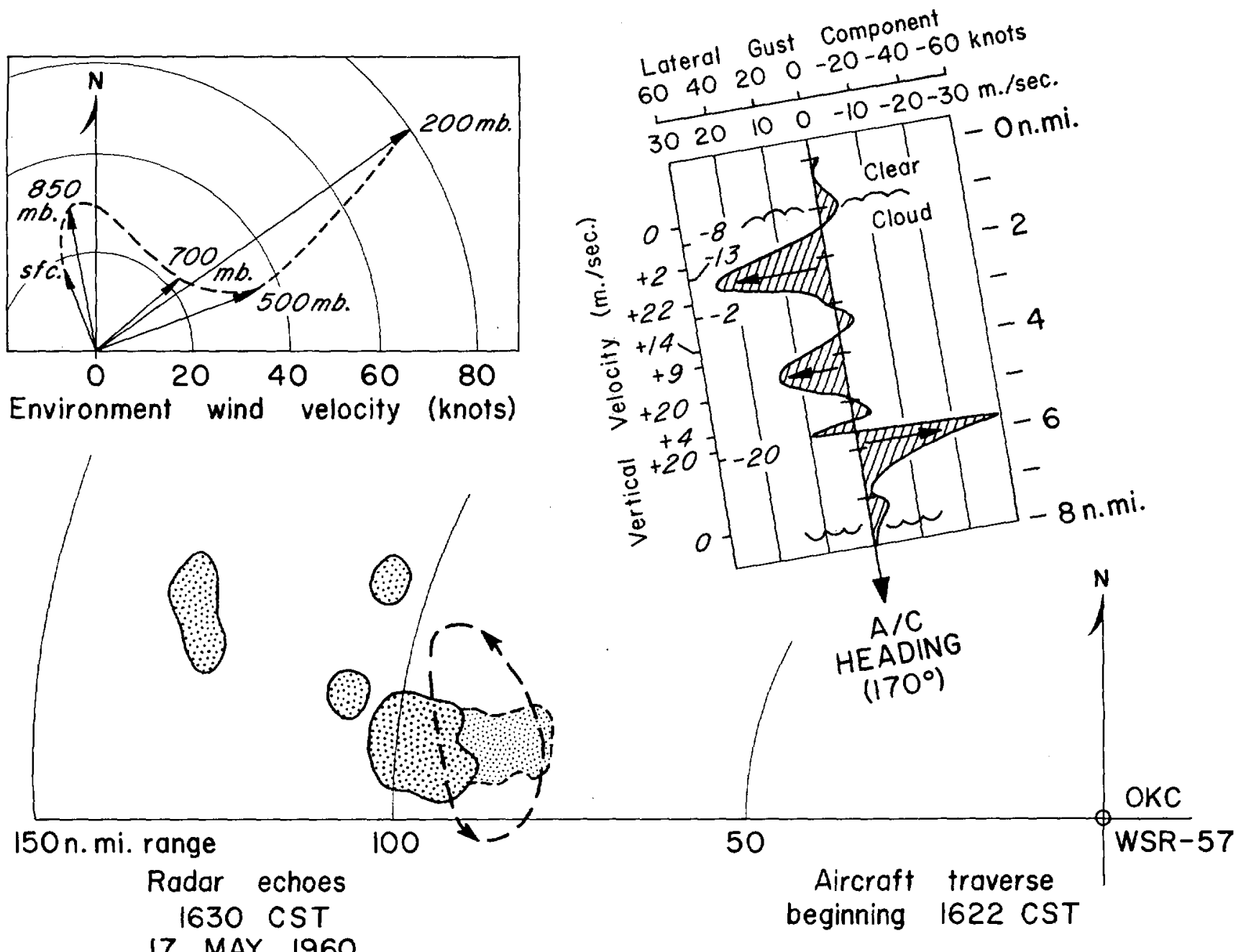

17 MAY 1960

FIGURE 17.-Radar echoes and other information pertaining to aircraft penetration on May 17, 1960. For description, see text.

Turbulence and other phenomena inside storms.-Penetrations of convective clouds were accomplished in spring 1960 by $T-33, F-102$, and F-106 aircraft, and in spring 1961 by an F-106 and a B-66. These planes were operated by the Aeronautical Systems Division (ASD) of the Air Force, having been instrumented by ASD, NASA, and (the B-66) Douglas Aircraft Company. In 1961, a T-33 lead plane (one of whose functions was to sample, for damaging bail, the intended path for supersonic penetration of the $F-106$ ), and a B-47 for radar and photography, supported the penetration aircraft. Aircraft were vectored by FAA controllers using a WSR-57 radar at Oklahoma City. The locations of the aircraft, identified by IFF beacon transponders, were displayed along with the storm echoes at flight elevation, for chosen gain settings [33].

The varying objectives of these flights were to record turbulence and to examine its effects on airframes, to study the effects of water and ice-crystal ingestion on jet engines, and to examine critically penetration procedures. Penetrations were carried out at levels ranging between 15,000 and $42,000 \mathrm{ft}$. During these initial efforts, aircraft were intentionally vectored so as to avoid the hardest cores as revealed by radar. In 1960, penetrations were made at subsonic speeds, while in 1961 emphasis was placed on supersonic speeds.

Turbulence-measuring aircraft were equipped with vanes having vertical and horizontal axes, mounted on a boom ahead of the nose. Data pertaining to horizontal and vertical accelerations of the aircraft, and also pitch, yaw, and roll angles, were recorded since the effects of attitude and changes of attitude must be subtracted out of the information recorded by these vanes. Because of the extensive amount of processing involved, only a limited amount of the recorded data has become accessible to NSSP at this time. Although the presently available 


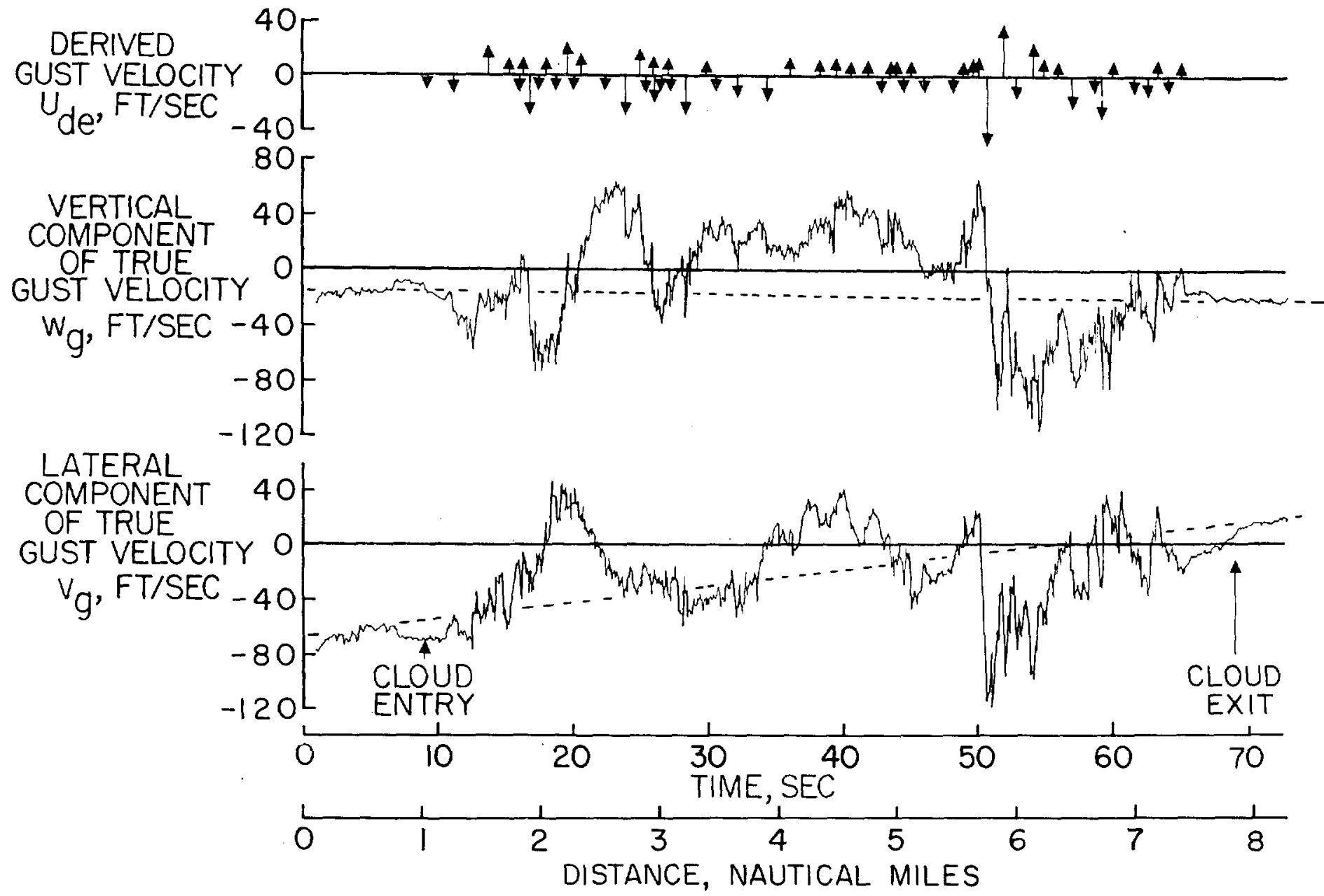

Frgure 18.-Derived gust velocities and time histories of vertical and lateral gust components for storm traverse at $39,000 \mathrm{ft}$., $1622 \mathrm{csT}$, May 17, 1960. (After Steiner and Rhyne [30].) For explanation of dashed lines which we have added to lower two diagrams, see text.

sample is too limited to permit firm generalizations concerning the physical processes in storms, the measurements are of great interest and highly suggestive.

Figure 18 shows an example [30] of the gusts measured during a T-33 penetration at 1622 CsT on May 17, 1960, through a storm about $100 \mathrm{n}$. mi. west of Oklahoma City. The flight path, at an altitude of 39,000 ft. m.s.l., is shown in relation to a radar echo tracing in figure 17 . The diameter of this storm, whose reported top was $45,000 \mathrm{ft}$., grew from about $8 \mathrm{n}$. mi. at the time of penetration, to $20 \mathrm{n}$. mi., $35 \mathrm{~min}$. later. Penetration was east of the most intense portion of the storm.

The nature of the gust measurements is such that although relative variations are considered reliable, the absolute values of gust velocity are subject to interpretation." For want of a better assumption, it would appear reasonable to assume that the gusts should be referred to zero values at the dashed lines which have been added to the two lower diagrams in figure 18. The following discussion is in terms of this assumption, which must be viewed with caution. (It is entirely possible that significant vertical and relative horizontal motions exist outside the cloud boundaries rather than the quiescent conditions just assumed.)

Figure 18 shows that the central part of the cloud was dominated by an updraft about $3 \frac{1}{2} \mathrm{n}$. mi. wide along the flight path, with descending motions within the cloud on both sides. Superimposed were small-scale gusts of appreciable amplitude, with very sharp gradients in places (see upper diagram for derived gust velocities, which are a measure of the accelerations imposed on the aircraft in passing through these gust gradients). The maximum gust found in Steiner's and Rhyne's analysis of 11 storm traverses in 1960 was upward at $208 \mathrm{ft}$./sec.

11 The components of gust velocity are determined as incremental values from the mean for the entire record; thus, the gust velocities may actually be referred to an assumed "zero". Additional uncertainties arise from measurements of airplane attitudes with gyros which are subject to drift and the necessity of determining airplane linear motions by time integration of accelerometer records. For example, small errors, when integrated over the time required for a traverse, can be magnified into an appreciable drift from the true values, even though the relative variations over short time intervals are faithfully dealt with. In the case of the vertical component, the systematic effect of this drift can be removed, by comparison of the indicated overall vertical movement of the aircraft with the difference between altimeter readings before and after penetration. There is, however, no such basis for removing the drift in the lateral gust components. Although the position of the zero reference is important for meteorological interpretation, its choice has little consequence for the measures of turbulence related to aircraft performance. For a concise account of gust-data reduction procedures, see Steiner and Rhyne [30]. 


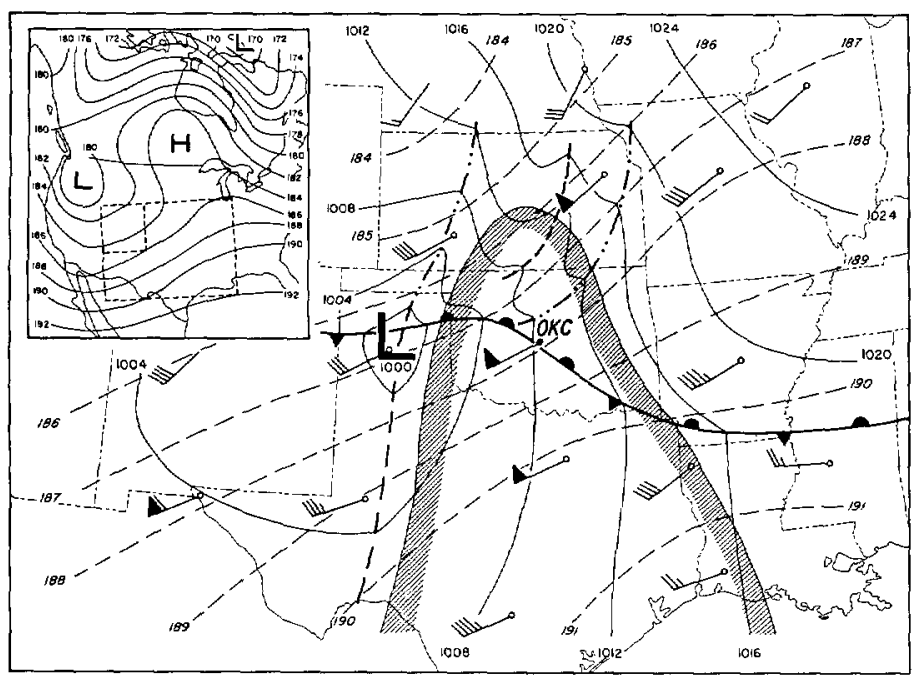

FIGURE 19.-Composite sectional chart for $1800 \mathrm{CST}$, May 4, 1961. Solid lines are isobars; fronts, squall lines, and troughs are indicated by conventional symbols. The hatching outlines the region of $10 \mathrm{gm} . / \mathrm{kg}$. or more moisture at $850 \mathrm{mb}$. Dashed lines are $500-\mathrm{mb}$. contours. Winds at $500 \mathrm{mb}$. are plotted with a pennant for $50 \mathrm{kt}$. and a barb for $10 \mathrm{kt}$. Inset map shows $500-\mathrm{mb}$. contours over most of North America. Location of sectional chart is shown by dashed lines in the inset.

(63 m./sec.), at $40,000 \mathrm{ft}$. in a cloud extending to 50,000 ft. on May 16.

These penetrations have yielded, for the first time, measurements of the lateral gusts within thunderstorms. Inspection of figure 18 indicates that the lateral components of gust velocity are also random in nature and have similar magnitudes as the vertical components of gust velocity. Steiner and Rhyne have, in fact, found that the power spectra for lateral and vertical gust components were essentially identical in several Oklahoma storms analyzed [30].

In the upper right inset to figure 17 , a smoothed profile of the lateral gusts (taken from the lower curve of fig. 18, with the zero line adjusted in the manner indicated earlier) is plotted relative to the aircraft heading. Significant values from a similarly smoothed vertical gust profile are plotted on the left side of the inset. Although the correlation is imperfect, this figure indicates that, on the whole, westward-directed gusts tend to be associated with upward motions, while the strongest eastwarddirected gust is identified with the strongest downward motion.

Insufficient information is at hand to show whether this kind of correlation generally characterizes thunderstorms. However, this association is what would be expected from the upward transfer of air having weak horizontal momentum, and the downward transfer of air having strong horizontal momentum (see upper left inset to fig. 17, which shows the strong vertical shear in the environment). It is apparent that further study of this kind of measurements will contribute greatly toward our understanding of the internal structure and dynamics of convective storms.

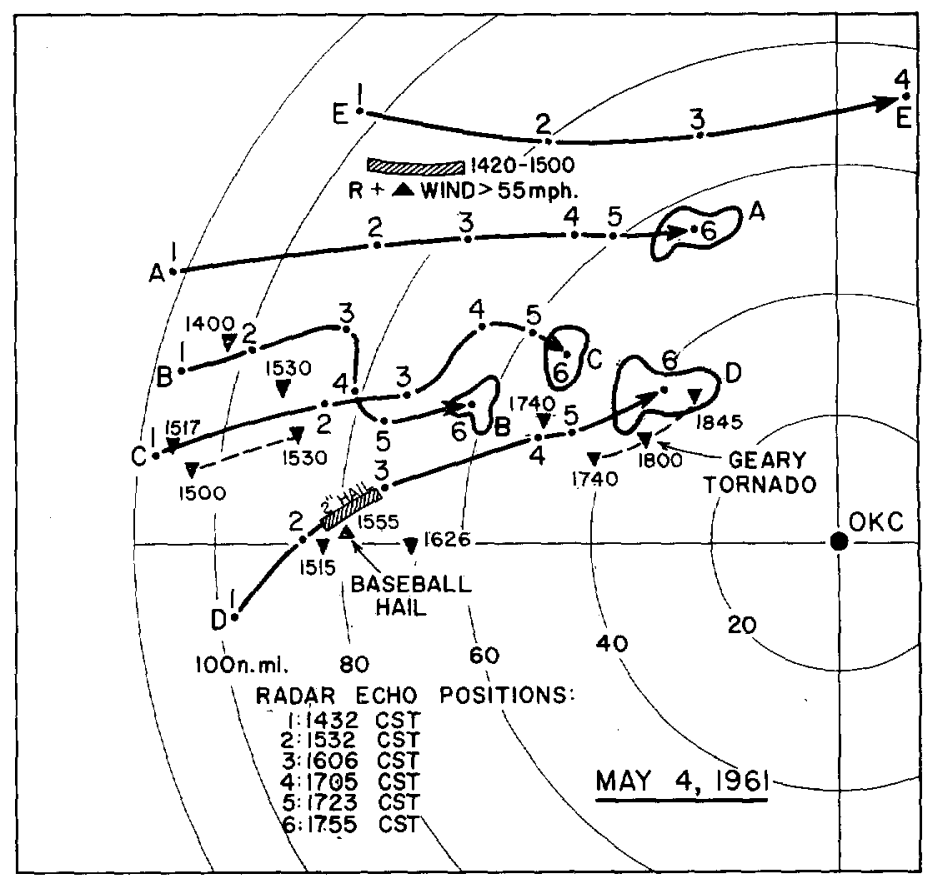

FIgURe 20.-Tracks of selected radar echoes between 1432 and 1755 Csr, May 4, 1961. Locations of reported tornadoes, wedges. (After Hamilton [17].)

One of the most interesting observations made by pilots of penetration aircraft concerns the apparent existence of large quantities of liquid water in the upper parts of cumulonimbus clouds $[25,26,28]$. Liquid water has been reported in squall-line clouds at heights around $40,000 \mathrm{ft}$., where ambient temperatures were $-45^{\circ} \mathrm{C}$. to $-52^{\circ} \mathrm{C}$. Since in-cloud air and water temperatures are not available, the full significance of these observations is not yet apparent. They have implications for such matters as the growth of water droplets and hail (it has generally been assumed that liquid water is not available above levels where the temperature is $-40^{\circ} \mathrm{C}$.), and the thermodynamic processes involved.

Pilot's reports indicate an association between the darkest parts of storm interiors and encounters with the heaviest rain and often with the heavier turbulence [26]. Considerable damage to aircraft components has at times resulted from liquid-water impingement. For example, in flights at speeds around Mach 1.6 (at which the impact pressure of water drops is about 1 ton $/ \mathrm{cm} .{ }^{2}$ ), the edges of rivet heads on the wing leading edge have been peeled back or broken off [25].

\section{CHARACTERISTICS OF STORMS AS REVEALED BY RADAR AND CLOUD PHOTOGRAPHS}

A program of radar surveillance was carried out in spring 1961 which included in addition to scope photography by regular Weather Bureau, Air Weather Service, and Air Defense Command stations, the operation of several radars in the Oklahoma City area. This involved the coordinated scanning of selected storms by PPI and RHI radars on different wavelengths and at variable 
antenna elevations and attenuation settings. Radars were calibrated against standard targets at intervals during the season. Time-lapse cloud photographs were made by cameras installed on aircraft, and by a pair of T-11 stereo cameras at ground sites near Norman, Okla., operated by GRD. In addition, Dr. T. Fujita secured a large number of carefully timed and positioned $35-\mathrm{mm}$. cloud pictures from the aircraft on several days. For some squall-line situations, strip photographs (going from horizon to horizon) are available from a U-2 aircraft (GRD) flown at high levels above the cloud tops.

Movements and development patterns of storms.-Studies by the Thunderstorm Project [9] demonstrated that small radar echoes move, with a. very high degree of correlation, along the direction of the mean wind in the 2,000 - to 20,000-ft. layer. This simple behavior does not necessarily characterize multicellular storms, in which propagation (development of new cells and dissipation of old ones) can contribute significantly to the motion of a storm cluster. The large storms of the Great Plains are typified by such propagation, and their patterns of movement and changes of form are of ten quite complicated.

Our analyses have not yet progressed to the point where any quantitatively-expressed generalizations of storm movements can be formulated, and only some general observations will be made here.

Figure 19 shows the $500-\mathrm{mb}$. flow and surface synoptic situation at 1800 CST May 4, 1961, a day with great convective activity. The paths of some selected storms are shown in figure 20. There is evidently no simple relationship between storm movements and the wind field. While the southernmost storms moved nearly along the direction of the $500-\mathrm{mb}$. flow, the ones farthest north moved nearly from west, with a pronounced component toward the right of the flow at all levels, over a period of several hours. Note the erratic behavior of storm " $B$ ", which for over an hour moved almost directly southward. It should be pointed out that this track represents the centroid of a cluster of echoes. Individual echoes of this cluster moved generally east-northeastward, and the southward movement of the cluster could be identified with a successive development of discrete storms on its south side combined with gradual dissipation of storms on the north side.

In a very general way, the movement of storms across the mean flow is understood to be due to a process of new growth on the right flank of the storm, attributed to certain physical processes arising from the veering of wind with height [24]. It has not been established, however, why different storms within a relatively small region should have movements so much at variance with one another.

Instances of discontinuous formation of squall lines, in the manner described by Boucher and R. Wexler [4] in their studies of radar data from New England and Jllinois, appear to be fairly common in the Great Plains region. In such an instance, new echoes are observed to form 10 to
$20 \mathrm{mi}$. in advance of an existing squall line, giving the impression of a temporary acceleration of the advancing squall-line boundary.

When a new thunderstorm cluster forms in an existing squall line, this is observed to occur much more frequently on the southern or southwestern ("upwind") end than elsewhere in the line. ${ }^{12}$

Reflectivity profiles in severe storms.-Atlas and Ludlam [2] have shown that simultaneous measurements of echo intensity by radars on different wavelengths, by virtue of their differing reflecting and attenuation properties, can provide an indication of precipitation intensities and probable hail content of a storm. Figure 21 a shows a characteristic example of the reflectivity profiles associated with a severe convective storm. These profiles were measured in the center one of the three cores in the radar tracing of figure $21 \mathrm{~b}$, in association with which a tornado occurred at Duncan, Okla. The reflectivity shown at this time was not particularly strong for a severe storm; it is intended only to illustrate the shapes of the profiles. In a large hail- or tornado-bearing storm, the reflectivity of the WSR-57 (10-cm.) radar is usually, as in this case, greater than that of the CPS-9 $(3-\mathrm{cm}$.) radar near the ground, the reverse being true in the upper levels.

From an analysis of 3-cm. radar data, Donaldson [11] found that the probability of hail and/or tornado occurrence in a storm is greatest when the reflectivity is large and the echo top is highest. In his study, the CPS-9 reflectivity was found on the average to decrease slowly up to about $20,000 \mathrm{ft}$., then to decrease rapidly with height. A pronounced peak at around 20,000 ft. was observed near the times of tornadoes. This observation applies to the maximum reflectivity observed in the storm as a whole, and not necessarily to the particular cell with which a tornado may be associated.

In this connection, it is of interest to note the result of an analysis by Ward [34], of the reflectivities (fig. 22a) in the storm echoes shown in figure $22 \mathrm{~b}$. The $3-\mathrm{cm}$. radar profile of the "mother" storm indicates a peak reflectivity above $20,000 \mathrm{ft}$., as in the case of figure 21 . In the particular "hook" echo identified with a tornado on the south side of the "mother" storm, however, the reflectivity was greatest in low elevations and decreased strongly with height. This suggests an absence or sparsity of large precipitation elements in the upper portions of the tornado-bearing cell. Many observations reported in the literature indicate that while heary rain and hail typically fall some distance north of tornado tracks, significant precipitation is apt to be lacking in the near vicinity of a tornado. Reports from volunteer observers indicated that large hail (diameter 2 in. or more;

$12 \mathrm{Mr}$. H. E. Foster (oral communication) confirms that this tendeney is well known to analysts of radar data. The Thunderstorm Project (19], pp. 78-79), in a study of 426 newecho formations on 8 days in Florida and Ohio, found some tendency for new cells to form preferably on the side of a preexisting radar echo toward which it was moving (on individual days, different preferred sectors were noted). In the sample involved, the winds aloft and the vertical shear through the cloud layer were generally weak, and these results are not considered comparable to the typical squall-line situation. 

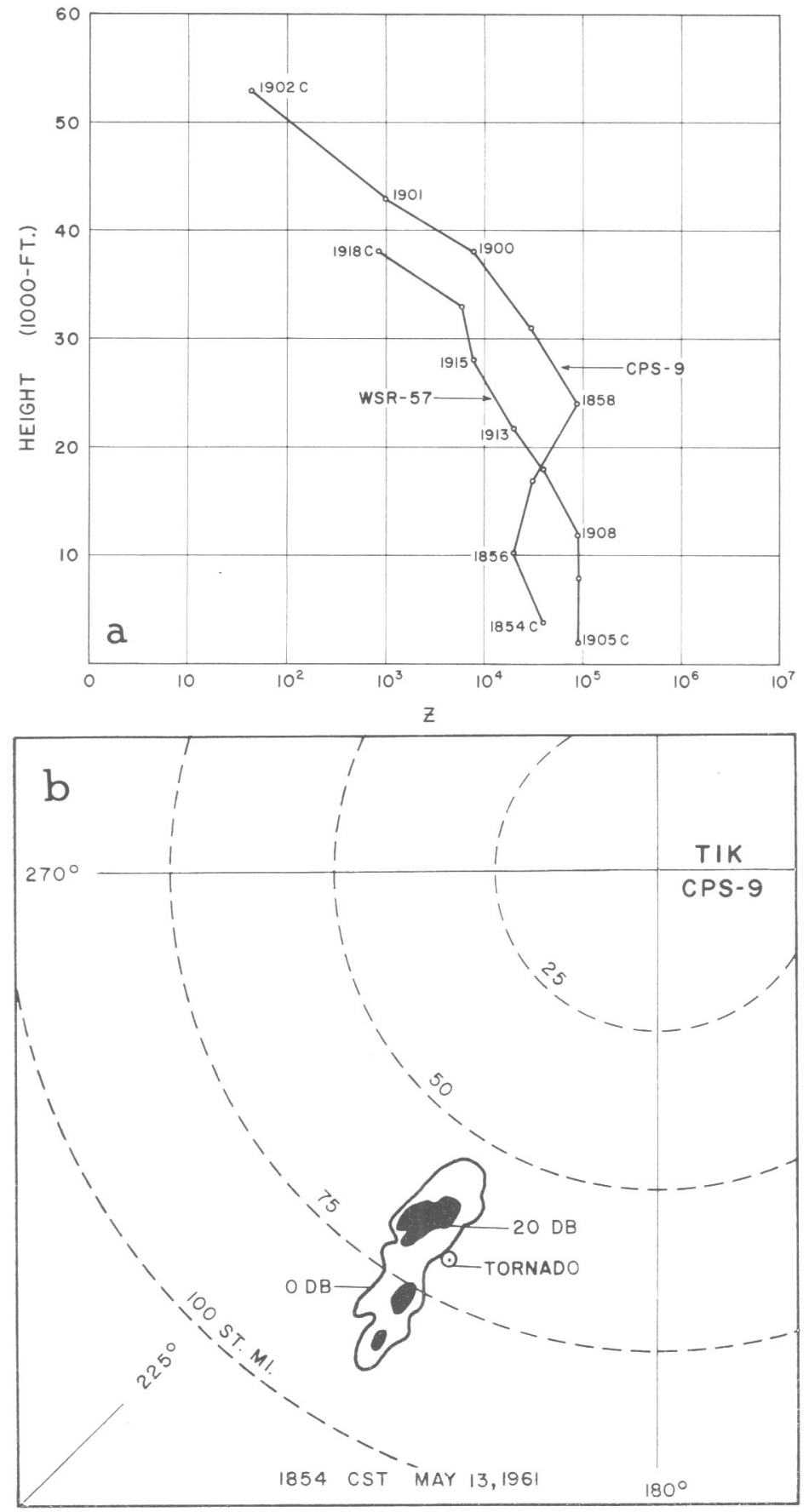

Frgure 21.-(a) Reflectivity proinles of central storm core in (b), showing radar echo contours at zero antenna elevation, 0 - and 20-db. attenuation of CPS-9 radar at Tinker AFB, Oklahoma. In (a), rain-equivalent reflectivity $(Z)$ in units of $m m .6 / \mathrm{m}^{3}$, computed at elevations marked on profiles at times shown.

in one locality baseball-sized) was discharged in this storm at an earlier time. The hail fall was close to the track of the radar storm center (storm " $D$ " in fig. 20), which corresponded nearly to the maximum-reflectivity core as seen by the $10-\mathrm{cm}$. radar; the principal tornado activity was, however, south of this track.

Three-dimensional structures of storms.-Present knowledge of the interior anatomy of large storms is exceedingly vague, even in regard to the arrangements of the main $684076-63-3$
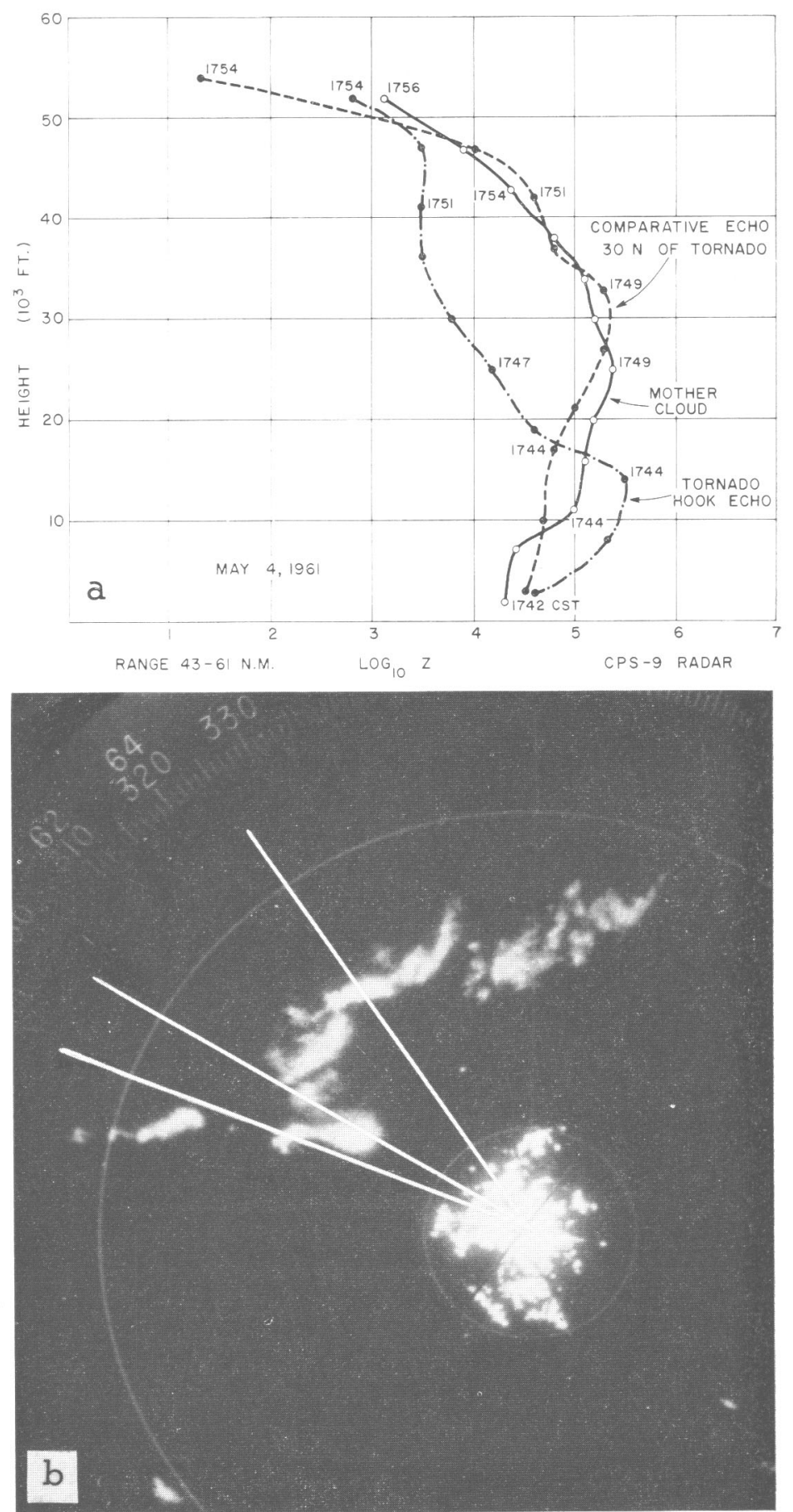

Figure 22.-(a) Radar reflectivity proifles in echoes intersected along azimuths marked in (b), a picture of the CPS-9 radarscope at Tinker AFB at $1741 \mathrm{csT}$ on May 4, 1961. (After Van Thullenar [33].)

updrafts and downdrafts. Aircraft measurements of wind velocities inside such storms are virtually nonexistent. It is hoped that analyses of lateral and vertical gust data of the kind shown in figure 18, together with data from balloon observations in storms, may be pieced together to yield a coherent picture of the interior workings of storms.

Valuable clues as to the probable flow patterns inside storms are provided by studies of their forms as shown by radar and cloud photographs, and of the radar reflectivities 

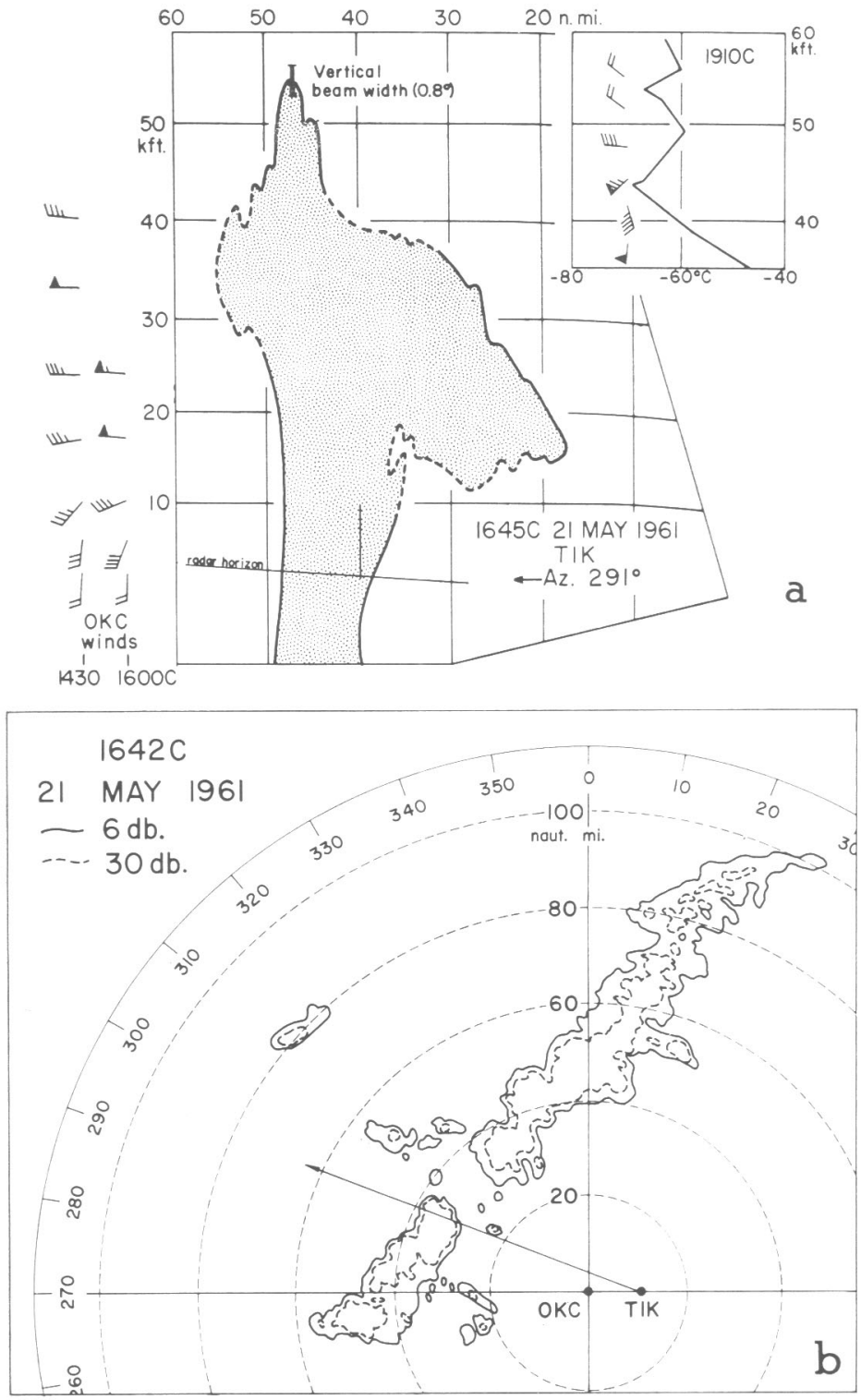

Figure 23.-(a) Tracing of FPS-6 RHI radar echo profile of element of squall line, along azimuth indicated in (b). In (b), tracing is from Oklahoma City WSR-57 radar, $0^{\circ}$ antenna tilt, contours at 6- and 30-db. attenuations. To left of (a), winds prior to squall-line passage at Oklahoma City; at upper right, portion of temperature and wind sounding just after storm passage; the balloon entered shelf of eirrus northwest of storm.

from which the distribution and character of the precipitation may be inferred. An excellent example of this kind of deduction is the analysis of a severe hailstorm over England by Browning and Ludlam [6]. The RHI radar profile of a squall-line thunderstorm, shown in figure 23a, exhibits some features in common with the storm they studied. This is a vertical section along the line indicated in figure $23 \mathrm{~b}$, approximately along the direction of the wind shear vector between the $850-$ and $200-\mathrm{mb}$. levels.

One of the remarkable features of this profile is the erectness of the main storm column. It is noteworthy that the highest turret, extending well above the tropopause in the surroundings, was located on the upshear
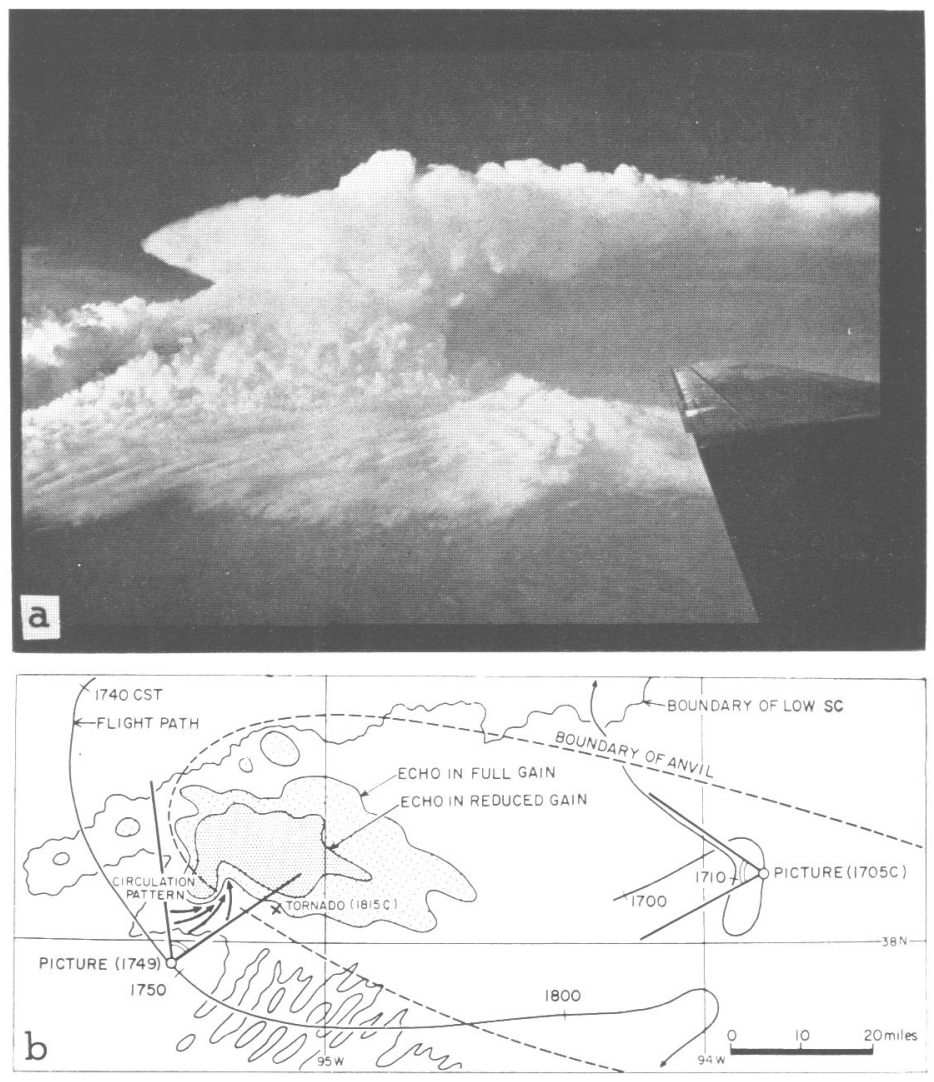

Figure 24.-(a) Photograph of large cumulonimbus near Chanute, Kans., at $1749 \mathrm{csT}$, April 21, 1961, from location shown in (b). (After Fujita [15].)

side of the storm. This is the typical location of growing turrets, which later drift downshear, as shown by the radar studies of Byers and Battan [8] and Browning and Ludlam [6], and by studies of photographs by Scorer and Ludlam [27].

The configuration shown in figure 23a might be taken to suggest that the main updraft, composed of air which entered the right-hand side of the storm in lower levels, was tilted in an upshear sense (toward upper left, in the figure) in its course toward the turret emerging from the storm top. An updraft slanting in this manner is only possible if the horizontal motion of the updraft air toward the right of figure 23a is smaller than the corresponding movement of the squall-line system. In that case, an element of air entering the lower part of the storm at the advancing edge would, while rising, have a relative motion toward the rear of the storm.

This supposition is consistent with indications from serial rawinsonde ascents embracing the later passage of this squall line at Oklahoma City. Analysis of the streamlines in a time section (considering the wind components normal to the squall line, the motions being taken relative to the moving system) suggested that most of the air entering the squall-line circulation did so below 750 $\mathrm{mb}$., moving upward in the rain zone and leaving toward the rear of the squall line above about $400 \mathrm{mb}$. This 

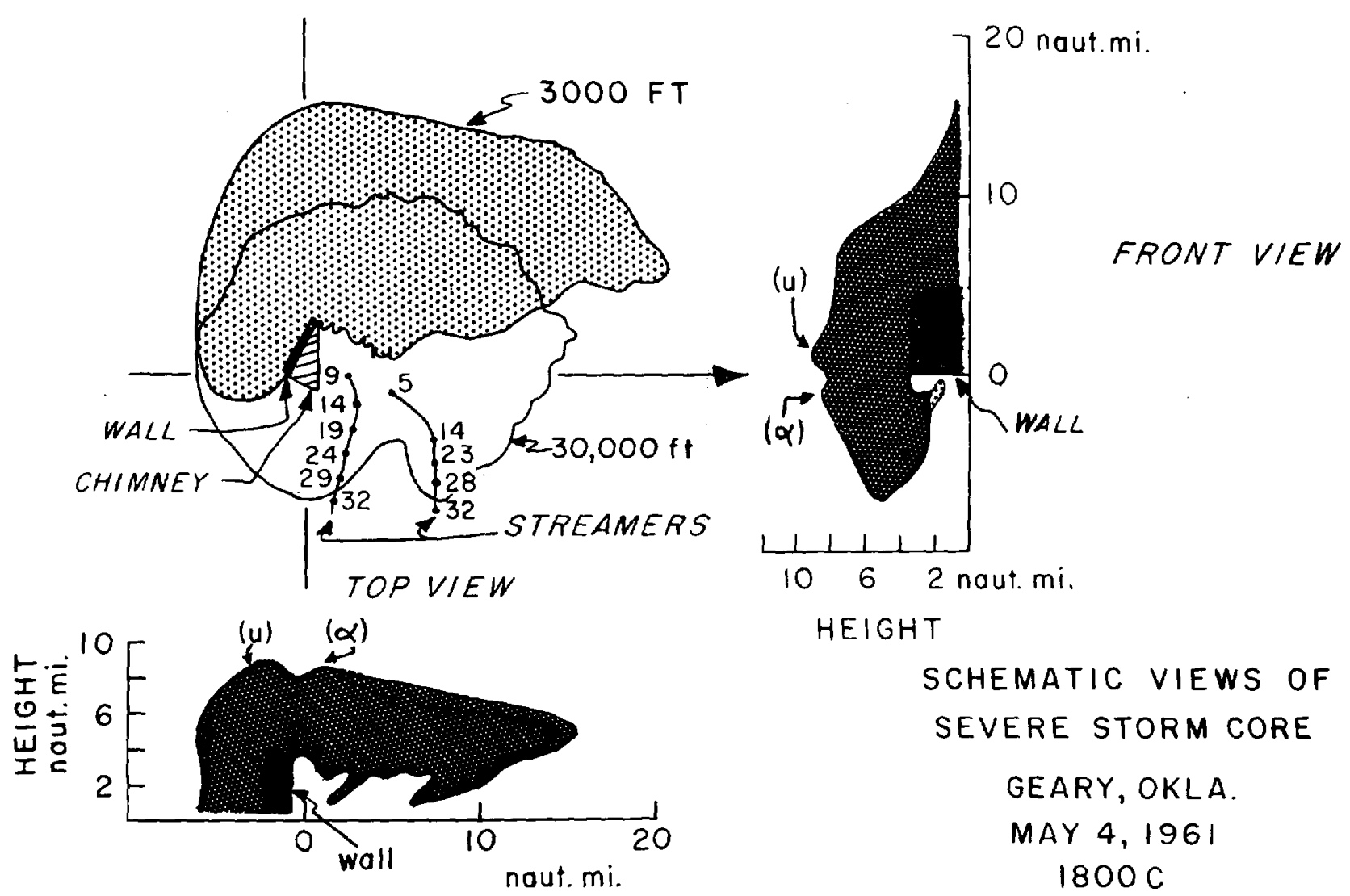
SCHEMATIC VIEWS OF SEVERE STORM CORE GEARY, OKLA. MAY 4,1961 $1800 \mathrm{C}$

Figure 25.-Schematic plan view, and view toward forward and right sides, of cumulonimbus which produced tornado at Geary, Okla., at $1800 \mathrm{CsT}$ on May 4, 1961. Arrow in top view indicates direction of movement of the storm; thin lines indicate motions of the tips of two streamers falling from overhang and moving toward storm, the heights at successive times being indicated in thousands of feet. (After Donaldson [12].)

evidence is, in itself, hardly conclusive since spot measurements are not necessarily representative of conditions characterizing the squall line as a whole. However, the same qualitative indication has been given by other rawinsonde ascents through squall-line thunderstorms. Note also the lateral gusts in figure 18, which suggested a much weaker westerly wind component within the top of, than in the environment of, the storm concerned.

A splendid example of the visual structure of a large isolated cumulonimbus is shown in figure 24a. This storm was circumnavigated by RFF aircraft at three levels. Photogrammetric analyses, and analyses of the meteorological measurements, are being carried out by Dr. T. Fujita at The University of Chicago.

Figure 24b shows certain aspects of this storm in plan view; the photograph in figure 24 a was taken from a DC-6 at $18,000 \mathrm{ft}$. on the southwestern side of the storm. This shows a massive anvil, with turrets protruding from its top, spreading an appreciable distance upwind and more than $100 \mathrm{mi}$. downwind from the main convective column (winds aloft at Topeka, about $60 \mathrm{mi}$. NW of the storm, were from $\mathrm{SW}$ about $40 \mathrm{kt}$. at $5,000 \mathrm{ft}$., increasing to $W$ $110 \mathrm{kt}$. at $42,000 \mathrm{ft}$.). Around the foot of the storm, there was a deck of stratocumulus in which the orientation of cloud rolls suggested a cyclonic circulation about the "hook echo" in the southwestern part of the storm (fig. $24 \mathrm{~b})$, possibly associated with the occurrence of a tornado a little farther east $25 \mathrm{~min}$. later.

The visible cloud boundary in figure $24 \mathrm{a}$, and the radar profile in figure 23a, both illustrate the great extent to which cumulonimbus clouds are typically deformed by the influences of vertical shear. In regard to figure $23 a$, it was indicated earlier that the updraft core probably leaned in an upshear direction. This suggestion is not in conflict with the impression gained by looking at the storm boundary as a whole, which would suggest a deformation in the opposite sense. As Hitschfeld [18] has indicated, the anvil or "plume" is essentially composed of cloud matter eroded from the active convective column in which condensation elements are produced. Due to the vertical transport of horizontal momentum, a storm core in which vertical motions are vigorous can resist the 
tendency to be sheared by the surrounding winds and thus remain erect $[18,24]$. The expelled detritus, after leaving the active convective core, drifts more readily with the wind. The downward slope of the radar plume in figure 23a toward the right is probably indicative of the gravitational settling of cloud elements, in the manner indicated by Hitschfeld. Note that the base of the plume was quite low. In flights of the DC-6 aircraft near cumulonimbi, mammatus clouds have often been observed at or below $18,000 \mathrm{ft}$.

Utilizing data from the FPS-6 radar at Tinker Air Force Base, Donaldson [12] has carried out a detailed study of the storms associated with tornadoes and hail northwest of Oklahoma City on May 4, 1961. (Some other aspects of this same situation have been mentioned earlier in connection with figs. 19, 20, and 22.)

A three-dimensional generalization of the storm which produced tornadoes around Geary, Okla., is presented in figure 25. This is representative of the main features during a considerable portion of the life of the storm, although there were changes in details. At Oklahoma City (60 n. mi. east of the storm core), the winds at this time were $185^{\circ} 45 \mathrm{kt}$. at $850 \mathrm{mb}$. and $260^{\circ} 55 \mathrm{kt}$. at 250 $\mathrm{mb}$, the shear vector between these levels being from $305^{\circ}, 62 \mathrm{kt}$.

In the southwestern corner of the low-level echo, there was a bulge of the kind often called a "tornado hook". On the advancing side of this bulge, a distinct "wall" or sharp boundary of the hard echo was present. Fast of this there was an echo-free notch or "chimney" (see side view and hatched region of top view in fig. 25) extending up to $18,000-20,000 \mathrm{ft}$. Farther east and south of the chimney, the "overhang" had a lower base, around 12,000$15,000 \mathrm{ft}$., pendant from which were "streamers" falling to low elevations.

The structure of this storm was in many ways similar to that of a large hail storm in England, studied by Browning and Ludlam [6]. By use of reports from a dense network of volunteer observers, they identified the "wall" as being associated with the onset of heavy hail. Donaldson found that the tornadoes observed by Ward [34] on this day occurred in the vicinity of the "chimneys", just ahead of the wall.

Browning and Ludlam interpreted an echo-free notch, analogous to the chimney in Donaldson's case (see also fig. 23a), as being the location where an intense updraft entered the storm, holding precipitation elements in suspension there while they were able to fall in the regions of downdraft or weaker updraft associated with the main storm column and the overhang. According to Donaldson's description of the case in figure 25 , the wall echo at the ground extended as much as $1 \mathrm{mi}$. ahead and $3 \mathrm{mi}$. to right of its position at $17,000 \mathrm{ft}$., suggesting horizontally advancing outflow from the downdraft. Ward, in traversing the region of heavy rain and small hail just behind the wall's forward edge, encountered westerly winds estimated at $60 \mathrm{kt}$. On the east side of the chimney, streamers falling from the overhang sloped toward the chimney, and the trajectories followed by the tips of these streamers curved toward the wall and chimney region in a cyclonic fashion (top view in fig. 25). These observations, taken together, suggest that the region on the right-hand side of the storm and ahead of the wall was one of pronounced horizontal convergence, in agreement with Browning's and Ludlam's interpretation.

The examples above serve to illustrate one of the main features of the severe storms characteristic of the spring months in the Oklahoma area, namely, their pronounced asymmetry. The larger and more intense storms appear to have highly organized structures frequently resembling that in figure 25.

\section{CONCLUDING REMARKS}

The observations and analyses discussed above illustrate selected aspects of the data obtained during NSSP field operations in 1960 and 1961. The cases discussed have been or will be treated in greater detail in separate publications by personnel of NSSP and the collaborating organizations.

In closing, it may be remarked that the examples shown above are, in most cases, related to the simpler kinds of observations which are of interest in the study of severe storms. In attempting certain operations thought at the time to be most suitable for answering specific questions, we have had the experience of straining the measuring systems beyond the limits of their design capabilities.

For instance, the seemingly obvious way to measure the inflow into or outflow from an individual thunderstorm would be simply to fly around the storm boundary, recording the necessary elements. Experience has shown that such a straightforward approach is often doomed to failure because the Doppler navigation system, on which positioning and wind computations depend, is subject to inaccuracies when the aircraft is turning appreciably. Reliable measurements can only be obtained, in this case, through a series of straight passes by the cloud flank. Storm circumnavigation then becomes a complicated and time-consuming operation, because of the requirement to make outside turns and to allow the measuring system to stabilize between successive passes.

This example illustrates only one of several serious difficulties with which we have been confronted. A need is indicated for developing instrumentation particularly suited to the problems of severe storm investigation. This is felt not only in the deficiencies of aircraft navigation, but also in regard to basic meteorological measurements. A general area in which present information is greatly inadequate, concerns the interior structures of convective storms. Intense gradients of physical quantities, the difficulties of measurement in a mixed air and liquid medium, and the hazards to which measuring platforms are subjected, impose great obstacles to successful observation.

The problem of convective storms, as is well known, must be attacked not only on the scale of the storm itself, 
but also with regard to the larger (cyclone-scale) circulations which generate and release instability. We know also that the forms, movements, patterns of development, and basic physical processes of convective storms are strongly influenced by the character of the wind, temperature, and moisture fields in their surroundings.

On all the scales concerned, studies of convective storms have been severely hampered by a lack of sufficient upperair observations, from which arises great uncertainty in defining some major aspects of the flow, temperature, and moisture patterns. A doubling of the density of the present network over an area covering several States, with provision for observations four times daily or at more frequent intervals when called for, is considered the minimum requirement for defining these patterns.

It appears that the problem of ascertaining the nature of, and ultimately improving the forecasting of, severe storms hinges not alone on the imaginative power of the investigators but also upon the acquisition of satisfactory observations on a scale much more massive than at present. The potential gain, affecting a wide variety of human activities, would seem to justify the expense and effort involved.

\section{REFERENCES}

1. A. B. Arnett, "Anomalous Wind Fields in the Immediate Environs of Tops of Severe Thunderstorms as Observed by Aircraft," Proceedings of the Second Annual Conference on Weather Effects on Aircraft Systems, Trenton, N.J., Sept. 18-19, 1962, pp. 71-80.

2. D. Atlas and F. H. Ludlam, "Multi-Wavelength Radar Reflectivity of Hailstorms," Quarterly Journal of the Royal Meterological Society, vol. 87, No. 374, Oet. 1961, pp. 523-534.

3. A. K. Blackadar, "Boundary Layer Wind Maxima and Their Significance for the Growth of Nocturnal Inversion," Bulletin of the American Meterological Society, vol. 38, No. 5, May 1957, pp. 283-290.

4. R. J. Boucher and R. Wexler, "The Motion and Predictability of Precipitation Lines," Journal of Meteorology, vol. 18, No. 2, Apr. 1961, pp. 160-171.

5. R. R. Braham and M. Draginis, "Roots of Orographic Cumuli," Journal of Meteorology, vol. 17, No. 2, Apr. 1960, pp. 214-226.

6. K. A. Browning and F. H. Ludlam, "Air Flow in Convective Storms," Quarterly Jaurnal of the Royal Meteorological Society, vol. 88, No. 376, Apr. 1962, pp. 117-135. See also "Radar Analysis of a Hailstorm," Technical (Scientific) Note No. 5, Contract AF 61(052)-254, Imperial College of Science and Technology, London, 1960, $106 \mathrm{pp}$.

7. I. W. Brunk, "The Pressure Pulsation of 11 April 1944," Journal of Meteorology, vol. 6, No. 3, June 1949, pp. 181-187.

8. H. R. Byers and L. J. Battan, "Some Effects of Vertical Wind Shear on Thunderstorm Structure," Bulletin of the American Meteorological Society, vol. 30, No. 5, May 1949, pp. 168-175.

9. H. R. Byers and R. R. Braham, Jr., The Thunderstorm, U.S. Weather Bureau, Washington, D.C., 1949, $287 \mathrm{pp}$.

10. R. M. Cunningham, "Cloud, Temperature, and Moisture Structure Details Through Two Dewpoint Fronts," paper presented at American Meteorological Society Conference on Severe Storms, Norman, Okla., Feb. 15, 1962.

11. R. J. Donaldson, Jr., "Analysis of Severe Convective Storms Observed by Radar," Journal of Metearology, vol. 15, No. 1, Feb. 1958, pp. 44-50.
12. R. J. Donaldson, Jr., "Radar Observations of a Tornado Thunderstorm in Vertical Section," National Severe Storms Project Report No. 8, U.S. Weather Bureau, Washington, D.C., Apr. 1962, 21 pp. (Preprint).

13. T. Fujita, "Results of Detailed Synoptic Studies of Squall Lines," Tellus, vol. 7, No. 3, June 1955, pp. 405-436.

14. T. Fujita, "Index to the NSSP Surface Network," National Severe Storms Project Report No. 6, U.S. Weather Bureau, Washington, D.C., Apr. 1962, 32 pp. (Preprint).

15. T. Fujita, "A Review of Researehes on Analytical Mesometeorology," Research Paper No. 8, Mesometeorology Project, Department of the Geophysical Sciences, The University of Chicago, Feb. 1962, 114 pp. (multilithed).

16. B. B. Goddard, "The Development of Aireraft Investigations of Squall Lines from 1956-1960," National Severe Storms Project Report No. 2, U.S. Weather Bureau, Washington, D.C., Feb. 1962, 34 pp (Preprint).

17. J. W. Hamilton, "Some Observations of Radar Echo Patterns Associated with Tornadoes in Oklahoma," paper presented at American Meteorological Society Conference on Severe Storms, Norman, Okla., Feb. 15, 1962 (mimeographed).

18. W. Hitschfeld, "The Motion and Erosion of Convective Storms in Severe Vertical Wind Shear," Journal of Meteorology, vol. 17, No. 3, June 1960, pp. 270-282.

19. W. H. Hoecker, Jr., "Three Southerly Low-Level Jet Systems Delineated by the Weather Bureau Special Pibal Network of 1961," Monthly Weather Review, vol. 91, 1963 (to be published).

20. J. T. Lee, "A Summary of Field Operations and Data Collection by the National Severe Storms Project in Spring 1961," National Severe Storms Project Report No. 5, U.S. Weather Bureau, Washington, D.C., Mar. 1962, 47 pp. (Preprint).

21. E. L. McGuire, "The Vertical Structure of Three Dry Lines as Revealed by Aircraft Traverses," Na'ional Severe Storms Project Report No. 7, U.S. Weather Bureau, Washington, D.C., April 1962, 10 pp. (Preprint).

22. G. S. MeLean, "Observation of Severe Convective Activity in a Squall Line," Bulletin of the American Meteorological Society, vol. 42, No. 4, Apr. 1961, pp. 252-264.

23. L. L. Means, "A Study of the Mean Southerly Wind-Maximum in Low Levels Associated with a Period of Summer Precipitation in the Middle West," Bulleiin of the American Meteorological Society, vol. 35, No. 4, Apr. 1954, pp. 166-170.

24. C. W. Newton and H. R. Newton, "Dynamical Interactions Between Large Convective Clouds and Environment with Vertical Shear," Journal of Meteorology, vol. 16, No. 5, Oct. 1959, pp. 483-496.

25. G. P. Roys, "Penetrations of Thunderstorms by an Aircraft Flying at Supersonic Speeds," National Severe Storms Project Report No. 13, U.S. Weather Bureau, Washington, D.C., Jan. 1963 (Preprint, in preparation).

26. P. W. J. Schumacher, "Radar Photographs and Gust Loads in Three Storms of 1961 Rough Rider," National Severe Storms Project Report No. 13, U.S. Weather Bureau, Washington, D.C., Jan. 1963 (Preprint, in preparation).

27. R. S. Scorer and F. H. Ludlam, "Bubble Theory of Penetrative Convection," Quarterly Journal of the Royal Meteorological Society, vol. 79, No. 339, Jan. 1953, pp. 94-103.

28. R. H. Simpson, "Ultra-Cooled Liquid Water in the Tops of Cumulonimbus Associated with Squall Lines and Hurricanes," paper presented at American Meteorological Society Conference on Severe Storms, Norman, Okla., Feb. 15, 1962 (mimeographed).

29. Staff, National Severe Storms Project, "National Severe Storms Project Objectives and Basic Design," National Severe Storms Project Report No. 1, U.S. Weather Bureau, Washington, D.C., Mar. 1961, 16 pp. (Preprint). 
30. R. Steiner and R. H. Rhyne, "Some Measured Characteristics of Severe Storm Turbulence," National Severe Storms Project Report No. 10, U.S. Weather Bureau, Washington, D.C., July 1962, 17 pp. (Preprint).

31. M. Tepper, "Pressure Jump Lines in Midwestern United States, January-August 1951," Research Paper No. 37, U.S. Weather Bureau, Washington, D.C., June 1954, $70 \mathrm{pp}$.

32. U.S. Weather Bureau, "National Severe Storms Project Operational Guide," Washington, D.C., 1961, 120 pp. (multilithed).

33. C. F. Van Thullenar, "The Use of Radar in the Control of
National Severe Storms Project Penetration Aircraft," Proceedings, 9th Weather Ratar Conference, Kansas City, Mo., Oet. 1961, pp. 199-205.

34. N. B. Ward, "Radar and Surface Observations of Tornadoes of May 4, 1961," Proceedings, 9th Weather Radar Conference, Kansas City, Mo., Oct. 1961, pp. 175-180.

35. H. Wexler, "A Boundary Layer Interpretation of the LowLevel Jet," Tellus, vol. 13, No. 3, Aug. 1961, pp. 368-378.

36. D. T. Williams, "Pressure Wave Observations in the Central Midwest, 1952," Monthly Weather Review, vol. 81, No. 9, Sept. 1953, pp. 278-289.

\section{Recent Articles in Other Weather Bureau Periodicals}

Mariners Weather Log, vol. 7

No. 1, January 1963:

"Persistence of Waves Along the East Coast of the United States," by J. M. Kipper and A. R. Gordon, Jr., pp. 1-12.

"North Atlantic Tropical Cyclones, 1962", by Howard C. Sumner, pp. $13-15$.

No. 2, March 1963:

"Cyclogenesis Along the Atlantic Coast of the United States," by James F. Andrews, pp. 43-46.

"Tropical Cyclones in the Eastern North Pacific, 1962," by Walter E. Benkman, pp. 46-49.

No. 3, May 1963:

"Typhoons of the Western North Pacific, 1962," prepared by Fleet Weather Central, Guam.

"The AGOR Class Oceanographic Research Vessels," prepared by Marine Survey Div., U.S. Naval Oceanographic Office.

Weekly Weather and Crop Bulletin, National Summary, vol. L

No. 3, January 2, 1963:

"Weather of the Year 1962," by L. H. Seamon, pp. 7-8.

No. 7, February 18, 1963:

"Weather Stations in United States," by J. H. Hagarty, p. 8. 